\title{
Financial Instability - a Result of Excess Liquidity or Credit Cycles?
}

Heebøll-Christensen, Christian

Publication date:

2011

Document version

Early version, also known as pre-print

Citation for published version (APA):

Heebøll-Christensen, C. (2011). Financial Instability - a Result of Excess Liquidity or Credit Cycles? Department of Economics, University of Copenhagen. 


\title{
Discussion Papers \\ Department of Economics \\ University of Copenhagen
}

\author{
No. $11-21$
}

Financial Instability - a Result of Excess Liquidity or Credit Cycles?

Christian Heebøll-Christensen

$\varnothing$ ster Farimagsgade 5, Building 26, DK-1353 Copenhagen K., Denmark

Tel.: +4535323001 - Fax: +4535323000

http://www.econ.ku.dk

ISSN: $1601-2461(E)$ 


\title{
Financial Instability - a Result of Excess Liquidity or Credit Cycles?*
}

\author{
Christian Heebøll-Christensen ${ }^{\dagger}$
}

August 25, 2011

\begin{abstract}
This paper compares the financial destabilizing effects of excess liquidity versus credit growth, in relation to house price bubbles and real economic booms. The analysis uses a cointegrated VAR model based on US data from 1987 to 2010, with a particulary focus on the period preceding the global financial crisis. Consistent with monetarist theory, the results suggest a stable money supply-demand relation in the period in question. However, the implied excess liquidity only resulted in financial destabilizing effect after year 2000. Meanwhile, the results also point to persistent cycles of real house prices and leverage, which appear to have been driven by real credit shocks, in accordance with post-Keynesian theories on financial instability. Importantly, however, these mechanisms of credit growth and excess liquidity are found to be closely related. In regards to the global financial crisis, a prolonged credit cycle starting in the mid-1990s - and possibly initiated subprime mortgage innovations - appears to have created a long-run housing bubble. Further fuelled by expansionary monetary policy and excess liquidity, the bubble accelerated in period following the dot-com crash, until it finally burst in 2007.
\end{abstract}

JEL Classification: C32, E51, E44, G21

Keywords: financial instability; housing bubbles; credit view; money view; cointegrated VAR model; impulse response analysis

${ }^{*}$ I have received valuable comments and suggestions from Michael Bergman and others, after two seminar presentations at the University of Copenhagen and one presentation at the 15th ICMAIF Conference, Crete, Greece, May 2011.

${ }^{\dagger}$ Department of Economics, University of Copenhagen, Øster Farimagsgade 5, Building 26, DK-1353 Copenhagen K, Denmark. Email: chc@econ.ku.dk 


\section{Introduction}

In the literature, financial crises are commonly found to be preceded and caused by financial instability, which is characterized as real economic booms and accelerating asset price inflation (Reinhart and Rogoff, 2009). However, the mechanisms of financial instability are still not settled. This paper focuses on the two major contradictory theoretical views on this matter - the money view and the credit view - and questions the relative importance of money versus credit for the building of financial instability. The debate between the two approaches is illustrated by the following two conflicting statements, in favor of the money and credit view, respectively:

"Theories that relate asset price booms to the volume of credit or to bank lending, rather than the quantity of money are misconceived." Congdon (2006)

and

"Money also means debt growth, and it is the debt that causes the financial instability." Cooper (2008).

The money view is based on the monetarist optimal portfolio idea, put forth by Friedman (1956). As modeled by Meltzer (1995), financial instability is defined as asset price bubbles caused by a spillover effect of excess liquidity, given by the money supply-demand balance. Meanwhile, assuming the irrelevance of capital structure, credit growth is purely seen as a natural manifestation of riskless shifts of purchasing power over time and various states of the economy. By contrast, the credit view assumes imperfect financial markets, meaning that capital structures are essential. Originating with the ideas put forth by Keynes (1936), Minsky (1993)'s financial instability hypothesis suggests a general instability of credit economies, in which financial instability is build through cycles of credit growth and asset price bubbles. More recent theories point to similar symptoms resulting from limited liabilities in credit contracts, e.g. the asset boom-bust theory by Allen and Gale (2000) and the model of credit cycles by Kiyotaki and Moore (1997). Using asset price bubbles as collateral, credit gives the possibility not just for shifting but also for creating purchasing power, unrelated to any real increase in value or voluntary savings in the economy. Common for the two views, however, structural changes of the financial and monetary systems of most industrial countries in recent decades are considered crucial to the mechanisms of financial instability.

The empirical literature analyzing these mechanisms is multifaceted, both regarding methods and results. In a cross-country setup, Claessens et al. (2011) find that, in particular, credit and house price cycles have a large impact on the amplitude and depth of real economic booms and busts. Similar results holds true for early warning systems, 
as shown by Borio and Lowe (2004). By contrast, in a panel model analysis by Adalid and Detken (2007) the results suggest that excess liquidity shocks are superior to credit shocks in determining asset price boom and busts.

An alternative to cross-country studies is to use a time series approach. One line of research uses the vector autoregressive (VAR) model to analyze the real economic effects of credit shocks. For example, Helbling et al. (2010) use a factor augmented VAR model on the G-7 countries and find significant effects of credit shocks on real global business cycles. This is a typical result for this type of analysis, in support of the credit view. Other VAR analyses allow for regime shifts, such as one carried out by Kaufmann and Valderrama (2007). They apply a Markov switching VAR model on Euro area and US data, including equity prices and credit growth, finding evidence of a two-stage regime in both areas. In their findings, credit shocks are particularly important in what they refer to as demand driven credit market regimes, which also supports the credit view. ${ }^{1}$ Furthermore, their findings are partly supported by Goodhart and Hofmann (2008), who used a panel VAR model to analyze 17 industrialized countries. Here, they find evidence of multidirectional links between house prices, money and credit, which are significantly stronger in booming credit markets and in the period after 1985. Their results support a varying influence of both money and credit and the importance of financial deregulation and innovation.

Another line of research using cointegration allows for specific focus on possible long-run financial instability building mechanisms. For example, Greiber and Setzer (2007) use a cointegrated VAR (CVAR) model to analyze US and Eurozone data. In both areas they find a stable money supply-demand relation, with significant liquidity spillover effects on house prices. They also include a credit measure in a robustness test, though their results suggest only the minor influence of credit shocks. Giese and Tuxen (2007) apply a similar monetarist CVAR model within a global framework, finding a surge in global liquidity from early 2001 with positive effect on global house prices. Other CVAR analyses focus on the relation between credit and house prices. Goodhart and Hofmann (2007) perform a CVAR analysis on 16 OECD countries, finding support for a stable long-term relation between credit and house prices in almost all countries. Here, they only test and find that causation runs from house prices inflation to credit growth, but the reverse causality is tested in similar, single-country CVAR analyses performed by e.g. Oikarinen (2009) for Finland, Gimeno and Martínez-Carrascal (2010) for Spanish and Gerlach and Peng (2005) for Hong Kong. With the exception of the latter, they all find that credit drives house prices in the long run, which supports the credit view. For the Finnish case, Oikarinen (2009) also finds a structural break of financial liberalization in the late 1980s, essential for the building of financial instability.

\footnotetext{
${ }^{1}$ Similar results are found by Atanasova (2003) using a non-linear threshold VAR model.
} 
The purpose of this paper is to analyze the macroeconomic mechanisms of financial instability within a CVAR model using US data. Based on two theoretical approaches to financial instability - the money and the credit view - I perform a comparative analysis focusing the links between house prices, GDP, money and credit. The contributions to the literature are multifold. Firstly, unlike earlier studies, I estimate a CVAR model on levels variables including both a real money measure, the real amount of credit, and real house prices. As a result, I am able to discriminate between and compare the hypothetical long-run relations and mechanisms derived from the two views on financial instability. Secondly, in concordance with some theorists, I test for and analyze time varying effects in the mode. Thirdly, I explicitly model persistent I(2) trends found in the data, seemingly related to structural changes of financial regulation and innovation. Earlier studies disregard the existence of I(2) trends even though house prices and leverage both theoretically and empirically can be argued to contain such overly persistent behavior. Finally, using impulse response analysis, I compare the different driving mechanisms in regard to shocks to the endogenous variables.

Overall, the results suggest that long-run house price movements are driven by real credit expansions, resulting from financial deregulation and innovation. Hence, in support for the credit view, capital structures are essential for increasing financial instability. I also find a stable money supply-demand relation. However, the implied excess liquidity is only important for financial instability after year 2000. Furthermore, the results support time-varying influence and interdependence between excess liquidity and credit growth, which could be an explanation for the various results found earlier in the literature.

The remainder of this paper is organized as follows: in Section 2 I discus the econometric methodology, and in Section 3 the theoretical considerations. In Section 4 I introduce the data and sample period, which leads to a further specification of the model in Section 5. The empirical analysis is found in Section 6 and 7, and in Section 8 I summarize and discuss the results.

\section{Methodology}

The analysis uses an I(1) cointegrated VAR model (CVAR) analyzing both the cointegration structure of the vector error correction representation (VEC) and the impulse responses functions $(I R)$ of the vector moving average representation (VMA). In what follows I shall generally use the terminology and notation set forth by Juselius (2007). 


\subsection{The reduced form VEC representation}

The CVAR model can be expressed in several forms. When cointegration relations are not accounted for, the model can be formulated as a $\operatorname{VAR}(k)$ model with $k$ autocorrelation lags:

$$
x_{t}=\sum_{i=1}^{k} \Pi_{i} x_{t-i}+\Phi D_{t}+\varepsilon_{t}
$$

where $x_{t}$ is a vector of $p$ endogenous variables at time $t=1,2, \ldots, T$, the $\Pi_{i}$ s are $p \times p$ matrices for the $i=1, \ldots, k$ lags of the model, and $D_{t}$ is a vector of deterministic components, e.g. a constant, a trend, impulse and shift dummies, with coefficients vector $\Phi . \varepsilon$ is a $p \times 1$ vector of multivariate normally distributed residuals, with a variance-covariance matrix $\Omega ; \varepsilon \sim N_{p}(0, \Omega)$.

The vector of endogenous variables comprises the logarithm of real house prices $(h)$, real credit $(k)$, real money $(m)$ and real GDP $(y)$, a nominal three-month t-bill rate $\left(i_{3 m}\right)$, the nominal own-rate on money $\left(i_{\text {own }}\right)$, and a 30 -year mortgage rate $\left(i_{30 y}\right)$. Hence, $x_{t}$ is a seven dimensional vector given by: ${ }^{2}$

$$
x=\left[h, k, m, y, i_{3 m}, i_{\text {own }}, i_{30 y}\right]^{\prime} .
$$

The CVAR model facilitates a characterization of the data variation into short, medium and long-run by the order of integration: $\mathrm{I}(0), \mathrm{I}(1)$ and $\mathrm{I}(2)$ respectively. To analyze cointegration relations, (1) with $k=2$ can be formulated as a VEC(1) representation:

$$
\Delta x_{t}=\Pi x_{t-1}+\Gamma_{1} \Delta x_{t-1}+\Phi D_{t}+\varepsilon_{t}
$$

where $\Pi=-\left(I-\Pi_{1}-\Pi_{2}\right)$ and $\Gamma_{1}=-\Pi_{2}$. Assuming for now that the level variables in (2) are at most $\mathrm{I}(1)$, a medium-run $\mathrm{CI}(1,1)$ cointegration hypothesis is equivalent to a reduced rank hypothesis of the $\Pi$-matrix. ${ }^{3}$ To analyze the cointegration relations, the $\Pi$-matrix can appropriately be written as the matrix product $\Pi=\alpha \beta^{\prime}$, where $\alpha$ and $\beta$ are $p \times r$ matrixes. Here, the $\beta$-matrix describes the structure of the $r$ medium-run cointegration relations, while the $\alpha$-matrix determines the corresponding, possible error correction or overshooting tendencies of each variable.

As will be demonstrated in the empirical analysis, some of the variables in (2) do

\footnotetext{
${ }^{2}$ These variables will be further motivated by theoretical consideration in Section 3 and specified in the data Section 4.

${ }^{3}$ Importantly, only the П-matrix has reduced rank and all terms in (3) are stationary. The reduced rank hypothesis can be verified by the I(1) trace test and the number of near unit roots in the characteristic polynomial of the П-matrix (unit roots), among others. If the П-matrix has a rank of $r<p$ and, hence, $s_{1}=p-r$ unit root then the model contains $r$ cointegration relations and $s_{1}$ I(1) common stochastic trends.
} 
evolve in a relatively persistent manner. Such persistence is incompatible with an I(1) process and indicates either an I(2) trend or structural breaks in the deterministic trends of the model. If this is the case, not only the П-matrix has reduced rank but also the $\Gamma$-matrix. ${ }^{4}$ As such, the number of unit roots in the $\Pi$-matrix, $p-r$, both include I(1) and I(2) common stochastic trends, i.e. $p-r=s_{1}+s_{2}$ where $s_{i}$ is the number of $\mathrm{I}(i)$ trends. Moreover, in (3) all terms except the residual will generally be $\mathrm{I}(1)$, hence, $\beta^{\prime} x_{t}$ does not only include purely medium-run $\mathrm{CI}(1,1)$ cointegration relations but also $\mathrm{CI}(2,1)$ and even long-run $\mathrm{CI}(2,2)$ cointegration relations. To see this, consider estimating the cointegration relations using the so-called $R$-form where the regressand and cointegration relations in (3) are concentrated out for short-run effects $\Delta x_{t-1}$ and the deterministic terms $D_{t}$ (Juselius, 2007, p. 292):

$$
\begin{aligned}
\Delta x_{t} & =B_{1}\left(\Delta x_{t-1}+D_{t}\right)+R_{0 t} \\
x_{t} & =B_{2}\left(\Delta x_{t-1}+D_{t}\right)+R_{1 t} .
\end{aligned}
$$

Using the residuals of these regressions, the R-form is given by:

$$
R_{0 t}=\alpha \beta^{\prime} R_{1 t}+\varepsilon_{t}
$$

When $x_{t} \sim I(2)$ and thus $\Delta x_{t} \sim I(1)$ it can be found from (4) and (5) that $R_{0 t} \sim I(0)$ and $R_{1 t} \sim I(2) .{ }^{5}$ Inserting (5) into (6) shows the following:

$$
\begin{aligned}
\underbrace{R_{0 t}}_{I(0)} & =\alpha \beta^{\prime}(\underbrace{x_{t-1}}_{I(2)}-B_{2} \underbrace{\left(\Delta x_{t-1}+D_{t}\right)}_{I(1)})+\varepsilon_{t} \\
& =\alpha(\underbrace{\beta^{\prime} x_{t-1}-\omega^{\prime}\left(\Delta x_{t-1}+D_{t}\right)}_{I(0)})+\varepsilon_{t}
\end{aligned}
$$

where $\omega=\beta^{\prime} B_{2}$. As the left hand side of (7) is stationary the same will be the case for the right hand side, i.e. $\beta_{i}^{\prime} R_{1 t} \sim I(0)$. For each of the $i=1, \ldots, r$ cointegration relations there are two ways to achieve this:

1. cointegration directly to stationarity, $\mathrm{CI}(2,2): \beta_{i}^{\prime} x_{t-1} \sim I(0)$ and $\omega_{i}=0$ or

2. polynomial cointegration: $\beta_{i}^{\prime} x_{t-1} \sim I(1)$ cointegrate with $\omega_{i}^{\prime}\left(\Delta x_{t-1}+D_{t}\right) \sim I(1)$, i.e. $\beta_{i}^{\prime} x_{t-1}-\omega_{i}^{\prime}\left(\Delta x_{t-1}+D_{t}\right) \sim I(0)$ with $\omega_{i}^{\prime} \neq 0$.

Here, the polynomial cointegration relations involve the first differences of the $\mathrm{I}(2)$ trends and will thus not be observable in an I(1) CVAR model. To determine whether $\mathrm{I}(2)$ trends are present in the data, I consider the roots of the П-matrix; if the roots are

\footnotetext{
${ }^{4}$ More specifically, when $x_{t} \sim I(2)$ a reduced rank restriction is imposed on the transformed $\Gamma$ matrix: $\alpha_{\perp}^{\prime} \Gamma \beta_{\perp}=\xi \eta^{\prime}$, where $\xi$ and $\eta$ are $(p-r) \times s_{1}$ matrixes.

${ }^{5}$ The I(1) trends in $\Delta x_{t}$ cancel when regressing on the I(1) variable; $\Delta x_{t-1}$, but the I(2) trends in $x_{t}$ cannot cancel when regressing on an I(1) variable.
} 
close to unity regardless of the number restricted I(1) trends, this is a sign of double unit roots, i.e. $\mathrm{I}(2)$ trends in the model.

There are different ways to explicitly deal with these problems in the I(1) CVAR model. One possibility, appropriate when the persistence is related to a few plausibly exogenous long-run break points, is to include deterministic terms. In (7) the first difference of the possible I(2) or broken trends are modeled by unrestricted shifts. Broken trends restricted to the cointegration relations are also included but should become insignificant if the trend breaks cancel in the cointegration, i.e. are similar for all variables. As a justifying point, there is no distinction between the broken trend scenario and the true I(2) trend scenario in a standard CVAR model; both cases result in I(2) symptoms. As an advantage, the method facilitates explicit analysis and economic interpretation of specific exogenous deterministic components. An important drawback, however, is that there is no clear way to test the structure and exact dates of the deterministic components within the CVAR model.

\subsection{The structural VMA representation}

To analyze how credit and liquidity shocks transmit through the system I will also perform an IR analysis on the VMA representation. From (3) the model can be reformulated as a reduced form VMA representation:

$$
x_{t}=C \sum_{s=1}^{t}\left(\varepsilon_{s}+\Phi D_{s}\right)+C^{*}(L)\left(\varepsilon_{t}+\Phi D_{t}\right)+\tilde{X}_{0}
$$

where $\tilde{X}_{0}$ is a vector of initial values, $C^{*}(L)=\Sigma_{j=0}^{t} C_{j}^{*} L^{j}$ determines the transitory effects from the stationary part of the process, while the $C$-matrix determines the permanent impact of shocks to the residuals, i.e. the common stochastic trends. The $C$-matrix can - as a parallel to the partition of the medium-run structure in the ח-matrix - be expressed as $C=\tilde{\beta}_{\perp} \alpha_{\perp}^{\prime}$ where $\tilde{\beta}_{\perp}=\beta_{\perp}\left(\alpha_{\perp}^{\prime} \Gamma \beta_{\perp}\right)^{-1}$. Assuming possible I(2) or broken trends are adequately modeled, the $\alpha_{\perp}^{\prime}$-matrix determines the construction of the $s_{1}$ common stochastic trends in relation to the residuals, while the $\tilde{\beta}_{\perp}$-matrix determines how each variable reacts to the common stochastic trends (Juselius, 2007, p. 255). When I(2) or broken trends are deterministically modeled, long-run trends will result from the accumulation of unrestricted shifts in $D_{s}$.

The model in (8) is formulated in reduced form, i.e. it is conditioned solely on predetermined variables (variables at time $t-1, t-2, \ldots$ ). As such, the model may systematically omit explanation of important simultaneous effects in the data, which appear as large non-diagonal elements in the variance-covariance matrix. However, IR analysis demands a diagonal variance-covariance matrix. Therefore, the $p$ residuals of the reduced form model are related to $p$ underlying linear independent structural shocks 
(Juselius, 2007, p. 278): ${ }^{6}$

$$
u_{t}=\left(\begin{array}{c}
u_{l, t} \\
u_{s, t}
\end{array}\right)=B \varepsilon_{t}
$$

where $u_{t}$ is a vector of $p-r$ permanent and $r$ transitory structural shocks, $u_{l, t}$ and $u_{s, t}$ respectively. $B$ is a $p \times p$ restriction matrix. Inserting (9) into (8) the model can be formulated as a structural VMA representation: ${ }^{7}$

$$
x_{t}=\sum_{i=1}^{t}\left(\tilde{C}\left[\begin{array}{l}
u_{l, i} \\
u_{s, i}
\end{array}\right]+C \Phi D_{s}\right)+C^{*}(L)\left(B^{-1}\left[\begin{array}{l}
u_{l, t} \\
u_{s, t}
\end{array}\right]+\Phi D_{t}\right)+\tilde{X}_{0}
$$

where $\tilde{C}=\tilde{\beta}_{\perp} \alpha_{\perp}^{\prime} B^{-1}$ and $C^{*}(L) B^{-1}$ determines the permanent and transitory effects respectively. While allowing for current effects, post multiplying by $B^{-1}$ introduces $p \cdot p$ new coefficients in the model. Just-identification therefore requires additional $p \cdot p$ restrictions on the $B$ and/or $\tilde{C}$-matrix. In the literature there are several ways of doing this (Lütkepohl and Krätzig, 2004, p. 163-171). In accordance with macroeconomic theory, these restrictions will be imposed so that the structural shocks satisfy three conditions: $i)$ linear independence $\left(u_{t} \sim N\left(0, I_{p}\right)\right)$, ii) they are separated into $p-r$ permanent and $r$ transitory shocks, and iii) the variables have a clear causal chain giving rise to clear economic interpretation. ${ }^{8}$ In the identified structural VMA representation (10), the IR functions determine the dynamics of a given variable when the model is hit by a given structural shock $\left(u_{i, t}\right)$. It is important to note that the additional restrictions, ordering and interpretations of the structural form cannot be tested, which is a critical and controversial point of the structural from (Juselius 2007, p. 232, 287; Lütkepohl and Krätzig 2004, p. 195).

\section{Theoretical considerations}

The theoretical literature on financial instability can be separated into different views related to different macroeconomic schools. Here, I will focus on the two contradictory theoretical perspectives: the money and the credit view. These will be addressed in

\footnotetext{
${ }^{6}$ Here I use the terminology employed by Juselius (2007, ch. 15) which is somewhat different from others; e.g. the $B^{-1}, C, C^{*}(L)$ and $\varepsilon$ in Juselius (2007) are equivalent to $B, \Xi, \Xi^{*}(L)$ and $u$ respectively in Lütkepohl and Krätzig (2004, ch. 4).

${ }^{7}$ Likewise the VEC representation can expressed in structural form: (3) multiplied through by the matrix $B ; B \Delta x_{t}=B \Gamma \Delta x_{t-1}+B \alpha \beta^{\prime} x_{t-1}+B \Phi D_{t}+u_{t}$, where $u_{t}=B \varepsilon_{t}, u_{t} \sim N(0, \Sigma), \Sigma=B \Omega B^{\prime}$.

${ }^{8} \mathrm{By}(p+1) p / 2$ restrictions on the $B$-matrix the first condition $\left(u_{t} \sim N\left(0, I_{p}\right)\right)$ is ensured. Here $(p-1) p / 2$ restrictions on the non-diagonal elements of the $B$-matrix assures independence, while another $p$ restrictions on the diagonal of the $B$-matrix assures a standardized distribution. In sum, these restriction are; $B^{\prime}=\left[\alpha^{\prime} \Omega^{-1} \alpha^{-1 / 2} \alpha^{\prime} \Omega^{-1},\left(\alpha_{\perp}^{\prime} \Omega \alpha_{\perp}\right)^{1 / 2} \alpha_{\perp}^{\prime}\right]$. The second condition is assured by another $(p-r) r$ zerorestrictions on the last $r$ columns of the $\tilde{C}$-matrix, while the third condition is assured by the remaining restrictions (Juselius, 2007, p. 278-279).
} 
relation to the empirical methodology and summarized in a theory-consistent CVAR framework.

\subsection{The money view}

The money view is related to the monetarist optimal portfolio idea, reformulated by Friedman (1956). It relies on assumptions of perfect financial markets and the theorem of capital structure irrelevance (Modigliani and Miller, 1958), while the quantity of money is seen as the central important variable in the economy.

Meltzer (1995) models the money view explicitly in relation to financial instability. On the one hand, this model assumes certain agent preferences for consumption and holdings of liquidity, assets and bonds, dependent on the current market situation, expectations, etc. On the other hand, there are opportunity costs of liquidity holdings, among others given by market interest rates. Jointly, agents hereby seek to maintain a portfolio balance in which marginal utilities equal marginal costs, which on a macroeconomic scale adds up to a money supply-demand balance. In this framework, financial instability is initialized by a positive monetary policy shock, causing a situation of excess money supply or, equivalently, excess liquidity of agents' portfolios. In this situation agents seek to rebalance to their optimal portfolios, selling off liquidity, with so-called excess liquidity spillover resulting in higher consumption, lower interest rates and booming asset prices. This is the central mechanism of the model, which will be considered in my empirical analysis. ${ }^{9}$

Importantly, these mechanisms are centered around the money supply-demand balance. In the empirical literature this relation is presented in different ways, including different measures of money, opportunity costs and transaction motives. In the empirical model in (3) including the variables in (2) I will focus on the following money supply-demand cointegration relation (constants are not reported):

$$
m_{t}=\beta_{11} y_{t}+\beta_{12} h_{t}-\beta_{13}\left(i_{3 m, t}-i_{\text {own }, t}\right)-\beta_{14}\left(i_{30 y, t}-i_{\text {own }, t}\right)
$$

where all $\beta_{1 i}$ s are expected positive; the quantity of money $\left(m_{t}\right)$ should increase when the short or long-term opportunity cost of money holdings decreases $\left(i_{3 m, t}-i_{\text {own }, t}, i_{30 y, t}-\right.$ $\left.i_{\text {own }, t}\right)$, and should decrease as a result of the transaction motive when the economic activity $\left(y_{t}\right)$ or housing wealth $(h)$ increases. ${ }^{10}$ This is in accordance with the analysis by Greiber and Setzer (2007), except that I also allow for opportunity cost from the long-term interest rate.

Excess liquidity is represented by money supply exceeding the level of money de-

\footnotetext{
${ }^{9}$ In addition, Meltzer (1995) considers different types of accelerating effect through higher market liquidity and lower uncertainty.

${ }^{10}$ Here, household wealth is approximated by the housing wealth.
} 
mand given by the right hand side of (11). The relevant hypothetical question is whether such a money supply-demand relation exists, whether excess liquidity affects real house prices positively and, furthermore, whether it leads to economic growth. Important to house prices, the money view assumes two medium-run stochastic trends in the economy: one being real economic supply shocks and the other being liquidity shocks to the real money supply or, alternatively, to the short-term interest rate controlled through the monetary policy. Liquidity shocks should have a medium-run positive effect on real house prices and real GDP.

\subsection{The credit view}

In contrast, the credit view assumes imperfect financial markets, motivated by the periods of financial deregulation before the Great Depression and after the 1970s. Capital and financial market structures - including the relative amount of credit in the economy - are key determinants of financial instability.

A central theory is the post-Keynesian financial instability hypothesis put forth by Minsky (1993). ${ }^{11}$ This theory assumes a capitalist dynamic economy in which economic growth is generated by ever-new profit-yielding investments. Investors are more or less funded by borrowing in the credit markets involving complex structures of credit contracts. In this framework, financial instability is driven by a growing inequivalence between the structure of payment commitments on credit contracts and the expected and realized cash flow of investments. Such arise during what Minsky refers to as basic cycles, which are comparable to standard business cycles. On top of this, working through several basic cycles, he also posits the existence of longer so-called super cycles, in which both market agents and policy markers adopt overly optimistic views on the stability of the economic system (Ferri and Minsky, 1992). ${ }^{12}$ This is what Minsky (1993) defines as financial instability, seen as growing leverage collateralized by asset price bubbles.

More recent theories incorporate similar mechanisms into a general equilibrium framework, e.g. the asset boom-bust theory proposed by Allen and Gale (2000) and the model of credit cycles put forth by Kiyotaki and Moore (1997). These theories assume limited liability in credit contracts whereby credit growth has a risk shifting effect from borrowers to lenders. More leverage and lower cost of capital means less net worth and lender liability. Ultimately, the less liability the more likely the lender is to seek overly risky investments, driving vicious circles of asset price bubbles and credit

\footnotetext{
${ }^{11}$ This theory builds on, among others, the credit view by J. A. Schumpeter, the debt-deflation theory by Fisher (1933), and especially Keynes (1936, ch. 11-12)'s general theory.

${ }^{12}$ This is what Ferri and Minsky (1992) call thwarting institutions. Some examples of such overly optimistic outlooks "The Great Moderation", "The New Economy" and "The East Asian Miracle". Similar mechanisms are argued by George Soros, among others.
} 
growth. Theories differ somewhat on whether this instability is self-generated by the economic system or initialized by exogenous shocks of various kinds: overoptimistic expectations of new economic regimes, monetary or structural policy changes etc. A fairly liberalized financial system is, however, a general premise.

Similar to the money view, the credit view argues for a cointegration relation relevant for financial instability. From the model in (3) including the variables in (2), I expect the following long-run relation, in line with the relation suggested by e.g. Goodhart and Hofmann (2007):

$$
h_{t}=\beta_{21}\left(k_{t}-y_{t}\right)-\beta_{23} i_{30 y}
$$

Here again, all $\beta_{2 i}$ s are expected to be positive; increasing the overall leverage of the economy $\left(k_{t}-y_{t}\right)$ and decreasing the cost of capital $\left(i_{30 y}\right)$ are both associated with a decrease in liabilities, more risk shifting between house owners and their lenders and, hence, rising real house prices.

The central hypothetical questions of the credit view in relation to (12) are whether such a stable relation exists, and whether house prices are error correcting, meaning that house prices are driven by leverage in the relation, and not just the other way around. Given the model in (3) including the variables in (2), I at least expect to find three long-run driving trends in the economy: real economic supply shocks, credit supply shocks, and shocks to the cost of home financing - resulting from the long-term or, possibly, short-term interest rate. The super cycle hypothesis by Minsky (1993) further argues that credit supply shocks will have a longer horizon than other shocks in the economy. However, the central question is whether credit shocks have positive effects on real house prices and on real GDP in the long run.

\subsection{Concurrence of the theoretical views}

The two theoretical views offer two competing hypotheses concerning the macroeconomic mechanisms of financial instability. Conditioned on the exact interpretation, the two views may or may not be mutually exclusive. Even thought the credit view states that credit is the central driving force of financial instability, there may still be a stable money demand relation. Likewise, from the perspective of the money view, housing has to be financed, which makes a natural relation between house prices and credit, though this does not suggest that credit is the cause of house price bubbles. It might also be the case that both mechanisms are at work simultaneously, though they may be more or less active at different points in time and in different stages of a business cycle. ${ }^{13}$

\footnotetext{
${ }^{13}$ For example, in two papers by Allen and Gale (1998 and 2000) the authors suggest that the credit view dominates the boom period while the money view - or at least quite similar effects - dominates the bust period.
} 
In the end, money and credit might be closely related, as argued by e.g. Greiber and Setzer (2007) and Cooper (2008, p. 53) (see the statement in the introduction). On the on hand, a situation of high liquidity might influence the net worth of firm and bring about low price fluctuations in financial and housing markets, which in turn eases the credit restrictions. On the other hand, though, new loans might be followed by new deposits, i.e. money creation. These are important hypotheses, which I will focus on in my empirical analysis below.

\section{Data}

The empirical analysis is based on monthly US data from 1987:01 to 2010:12. The model includes real credit in levels, defined as real debt outstanding to nonfinancial sectors $(k)$. For the nominal to real calculation I generally use CPI. The quantity of money is modeled as the real M2M $(m)$, i.e. M2 excluding small time deposits, as suggested by Greiber and Setzer (2007), among others. The M2M measure is used in order to avoid the problems of "the missing money of the 1990s" (Carlson and Keen, 1996; Greiber and Lemke, 2005). ${ }^{14}$ Real economic activity is modeled by real GDP $(y)$. For asset prices I include real house prices $(h)$, motivated by several earlier findings that financial crises are typically associated with the burst of house price bubbles (Claessens et al., 2011). Along the lines of US monetary VAR models, I include the nominal own rate on money $\left(i_{\text {own }}\right)$ and a nominal three-month t-bill rate $\left(i_{3 m}\right)$ (Greiber and Setzer, 2007). In the end, to model the cost of home financing, I include a nominal Freddie Mac 30 year fixed mortgage rate $\left(i_{30 y}\right) .{ }^{15}$ Housing prices, credit and GDP are ChowLin interpolated from quarterly to monthly data using proxies of higher frequency. The details and data sources are shown in Appendix A, and the seven variables of the model are shown in levels and first differences in Figures 1 and 2, respectively.

Looking at the graphs from a statistical point of view, there seems to be some persistent and synchronic breaks in real house prices and real credit, indicating some I(2) or broken trends in these variables. The remaining variables seem quite stationary in the first differences. These characteristics will be of special focus in my empirical analysis below.

\footnotetext{
${ }^{14}$ In the beginning of the 1990s, because of financial innovation and deregulation, small time deposits were substituted by different types of mutual fund products outside of the standard money measure, M2.

${ }^{15}$ For the home financing costs, I have chosen a long-term fixed mortgage rate in order to focus on relatively risk free financing. One might argue for the use of weighted portfolio interest rates, i.e. partly fixed and partly flexible mortgages.
} 
Figure 1: The variables of the model in levels
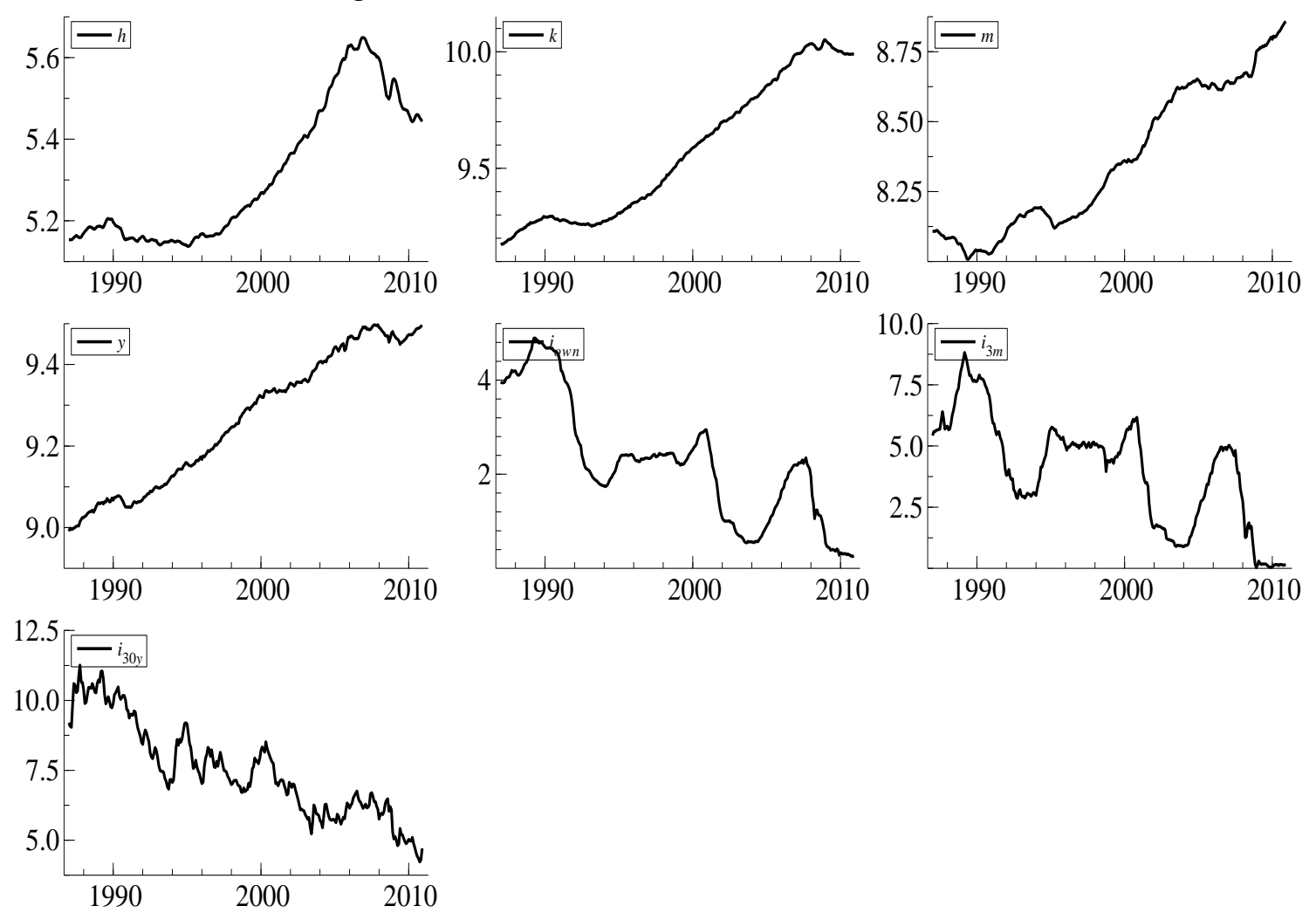

Figure 2: The variables of the model in first differences
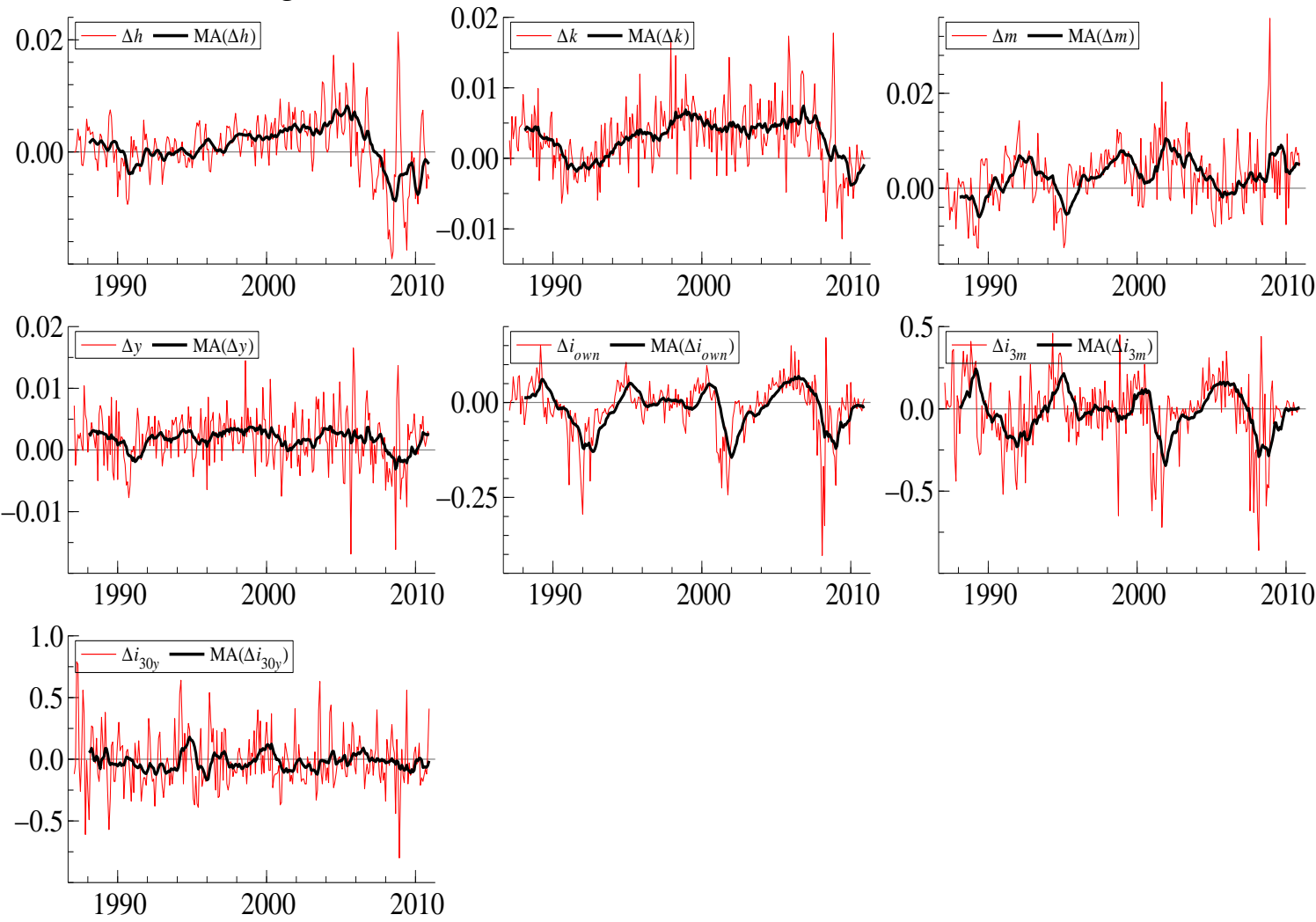

Note: MA indicates 12 month moving averages. 


\subsection{The sample period and economic regimes}

In the CVAR model it is important to have a relatively constant economic regime and, hence, reasonably constant relations between the model variables (Juselius, 2007, p. 149). However, this might not be true for recent decades. The early 1980s marks the beginning of "The Great Moderation", meaning a more stable economic and monetary policy regime. ${ }^{16}$ In addition, it marks the revival of a belief in market efficiency, both in the US and in most other industrialized countries. This tendency brought about substantial financial deregulation and innovation, possibly affecting the economic regime throughout the sample period. According to Chomsisengphet and Pennington-Cross (2006) and Temkin et al. (2002), three reforms are of particular importance, primary related to the Reagan deregulation period of the 1980s:

1. The Depository Institution Deregulation and Monetary Control Act of 1980, removing a deposit interest rate ceiling, originally established back in the 1930s.

2. The Alternative Mortgage Transaction Parity Act of 1982, generally allowing for variable interest and balloon payment on loans.

3. The Tax Reform Act of 1986, allowing for special tax deduction of mortgage interest payments.

One later reform from the post-Reagan era was also highly influential (Gorton, 2008):

4. The Gramm-Leach-Bliley Act of 1999, which eliminated the competition between traditional banks, investment banks and insurance companies.

These reforms, together with similar reforms in other industrialized countries, removed substantial credit rationing and market constrains, making way for financial innovations and the general development of national and international capital markets. As one important example, subprime mortgages eased credit conditions substantially by introducing a new segment of homeowners to the market (Gorton, 2008). Subprime lending started in the beginning of the 1990s, with a rapid growth of $760 \%$ for home purchases from 1993 to 1998.

The data shown in Figures 1 and 2 suggest that these structural changes, together with known historical crisis periods, seem to coincide with somewhat synchronous trend breaks in real credit and real house prices. The financial deregulations of the 1980s are associated with high credit growth and notable house price inflation early in the sample period. In the early 1990s, the savings and loan crisis (S\&L) induced a brief period of almost zero credit growth and low house price inflation. ${ }^{17}$ Beginning in the mid-1990s,

\footnotetext{
${ }^{16}$ In the period before, the quantity of money was both the target and the primary monetary policy instrument, i.e. "The Great Inflation".

${ }^{17}$ The saving and loan crisis refers to the failure of 747 savings and loan ("thrift") mortgage lending associations in the US in the late 1980s and early 1990s. The total cost was $\$ 87.9$ billion for resolving.
} 
the situation again changes to a regime of high credit growth and house price inflation, possibly caused by new financial innovations, such as the subprime mortgages. This trend continues until the global financial crisis, interestingly, unaffected by the dot-com crash in the beginning of the 2000s. From the global financial crisis onwards, real credit and especially real house prices fall rapidly.

Considering the other variables the picture becomes less clear. However, the three crisis periods - the S\&L crisis in the early 1990s, the dot-com bust in the early 2000s, and the global financial crisis - all seem associated with low economic growth and falling interest rates. Specifically, when trying to explain the increasing financial instability preceding the global financial crisis, many macroeconomists point to the period of expansionary monetary policy following the dot-com crash. This tendency is clearly seen in the development of the short-term interest rates from 2002 to 2005.

\section{Model specification}

In this section I specify the model including lag length, cointegration rank and number of stochastic and deterministic trends in the model.

\subsection{General specification}

First of all, to determine the lag length of the model I consider the Schwarz and HannanQuinn information criteria together with the LM test for autocorrelation. The information criteria (not reported) both indicate a lag length of $k=2$, while the LM test indicates $k=3$. In the following, I therefore assume a lag length of $k=2$. Furthermore, I check for extraordinary large residuals in the model. For the following ten dates at least one residual violates the normality assumption: ${ }^{18}$ 1992:07, 2001:09, 2005:09, 2005:11, 2006:09, 2008:02, 2008:05, 2008:08, 2008:10, 2008:11. These dates can all - more or less - be related to unusual historical events: the S\&L crisis in the early 1990s, the terror attacks of 9/11, shocks to the inflation rate from 2005 to 2006, and especially the global financial crisis of 2008. Including unrestricted impulse dummies for these dates, I further test the normality assumption. As seen in Table 1, the multivariate Doornik-Hansen test rejects the general normality of the model. When considering the multivariate LM tests this non-normality seems related to some degree of general heteroscedasticity. Considering univariate tests (not reported), the short-term interest rate variables in particular seem to display some over kurtosis $(>3)$, while several variables contain ARCH effects. ${ }^{19}$ As these types of non-normalities should not present a problem

\footnotetext{
${ }^{18}$ In accordance with the literature, these are residuals larger than 3.5 standard deviations.

${ }^{19}$ These results are available upon request form the author.
} 
for the interpretation and estimation, the model seems fairly well specified (Juselius, 2007, p. 75, 110).

Table 1: Misspecification tests

\begin{tabular}{|c|c|c|c|c|c|}
\hline \multicolumn{6}{|c|}{ Multivariate tests } \\
\hline Normality & & utocorrelation & & Heteroscedas & icity (ARCH) \\
\hline $\mathrm{DH}: \chi^{2}(14)$ & $\operatorname{LB}(82): \chi^{2}(3381)$ & $\operatorname{LM}(2): \chi^{2}(49)$ & $\operatorname{LM}(4): \chi^{2}(49)$ & $\operatorname{LM}(2): \chi^{2}(1568)$ & $\operatorname{LM}(4): \chi^{2}(3136)$ \\
\hline $\begin{array}{c}177.225 \\
{[0.000]}\end{array}$ & $\begin{array}{c}3859.001 \\
{[\mathbf{0 . 0 0 0}]}\end{array}$ & $\begin{array}{c}68.211 \\
{[0.036]}\end{array}$ & $\begin{array}{l}47.467 \\
{[0.535]}\end{array}$ & $\begin{array}{c}1936.388 \\
{[\mathbf{0 . 0 0 0}]}\end{array}$ & $\begin{array}{c}3752.009 \\
{[\mathbf{0 . 0 0 0}]}\end{array}$ \\
\hline
\end{tabular}

Note: DH is a Doornik-Hansen test; LB is the Ljung-Box; LM(k) is a LM test for autocorrelation and ARCH of order $k$. Rejection of the null hypothesis on a $5 \%$ significance level are marked bold.

\subsection{Cointegration rank and stochastic and deterministic trends}

To test the cointegration rank, Table 2 shows the trace test and the largest unrestricted root calculation of the model. While the trace test clearly indicates a rank of $r=3$, the roots of the model are found to be close to unity, regardless of the number of restricted I(1) trends. This is a clear sign of I(2) or broken trends in the data. ${ }^{20}$ As an indication of the origin of these trends, Table 3 below shows univariate Dickey-Fuller tests of all variables in first differences. Only for real house prices and real credit the univariate hypothesis of an I(2) trend cannot be rejected (for real credit not even on a 10\% significant level). This is in accordance with previous presumptions from the data Section 4 and the theoretical considerations given in Section 3: real house prices and real credit evolve in relatively persistent cycles, influenced by crisis periods and exogenous structural policy changes. These persistent cycles seem related to a few simultaneous and clearly defined breaks in the variables, and I therefore add deterministic components in order to model these structural breaks.

Table 2: I(1) trace test and the unrestricted root calculation

\begin{tabular}{l|cccccccc}
\hline $\boldsymbol{r}$ & $\mathbf{0}$ & $\mathbf{1}$ & $\mathbf{2}$ & $\mathbf{3}$ & $\mathbf{4}$ & $\mathbf{5}$ & $\mathbf{6}$ & $\mathbf{7}$ \\
$\boldsymbol{p}-\boldsymbol{r}$ & $\mathbf{7}$ & $\mathbf{6}$ & $\mathbf{5}$ & $\mathbf{4}$ & $\mathbf{3}$ & $\mathbf{2}$ & $\mathbf{1}$ & $\mathbf{0}$ \\
\hline$p_{\text {Bart }}^{*}$ & 0.000 & 0.000 & 0.001 & $\mathbf{0 . 3 5 7}$ & 0.325 & 0.882 & 0.614 & - \\
$\rho_{\text {max }}$ & 0.879 & 0.974 & 0.956 & 0.986 & 0.987 & 0.993 & 0.989 & 0.980
\end{tabular}

Note: $p_{\text {Bart }}^{*}$ is the Bartlett corrected trace test and $\rho_{\max }$ is the largest unrestricted root of the ПI-matrix.

Table 3: Dickey-Fuller test for the variables in first difference

\begin{tabular}{c|ccccccc}
\hline & $\Delta h$ & $\Delta k$ & $\Delta m$ & $\Delta y$ & $\Delta i_{\text {own }}$ & $\Delta i_{3 M}$ & $\Delta i_{30 y}$ \\
\hline$D F$ & -2.70 & -1.81 & $-3.62^{* *}$ & $-3.99^{* *}$ & $-3.68^{* *}$ & $-4.07^{* *}$ & $-5.47^{* *}$ \\
\hline
\end{tabular}

Note: $i)$ Significant level and critical values: $1 \% \approx-3.45^{* *}, 5 \% \approx-2.87^{*}, 10 \% \approx-2.57$. ii) All regressions include 11 lags.

As mentioned earlier, no appropriate test is able to determine the structure and dates of deterministic components within the CVAR model. As a hypothetical broken trend

\footnotetext{
${ }^{20}$ Other (not reported) determinants of I(2) trends gives somewhat the same result; the I(2) trace test and a comparison of the cointegration relations on standard form and $R$-form. These results are available upon request form the author.
} 
seem more prominent in the real credit variable, I run a simple univariate two-stage Markov switching process on real credit growth, including only a switching constant. ${ }^{21}$ Table B.1 in Appendix B shows the regime classification of the regression. In general, I find three break points: 1990:01, 1993:07 and 2008:01, giving rise to the following four regimes, related to different historical events:

1987:01 - 1989:12: Influenced by the financial deregulation of the 1980s, the late 1980s was a period characterized by high credit growth and house price inflation.

1990:01 - 1993:06: Partly as a result of the preceding credit boom, the early 1990s was dominated by the S\&L crisis, low credit growth and real house price deflation.

1993:07 - 2007:12: Also facilitated by financial deregulation of the 1980s, new financial innovations - especially subprime lending - started spreading from 1993 resulting in a prolonged period of substantial credit growth and house price inflation.

2008:01 - 2010:09: The global financial crisis and demise of "The Great Moderation".

To account for these structural breaks, I include three unrestricted shifts and test for broken trends restricted to the cointegration space in 1990:01, 1993:07 and 2008:01. As shown in Table 4 below, I cannot reject the multivariate test for exclusion of all broken trends in the cointegration space, while the broken trend in 1993:07 is only borderline excludable in the univariate tests. In the model only including the three unrestricted shifts, Table 5 further shows the trace test and the unrestricted root calculation. The largest unrestricted root now falls to around 0.9 in the model including four restricted I(1) trends. Hence, in spite of a quite large unrestricted complex pair of roots (for $r=3$ ), the I(2) symptoms are substantially diminished at least. At the same time, the number of common stochastic trends seems unaltered when compared to the model without unrestricted shifts, indicating that the stochastic I(2) or broken trends are successfully accounted for by deterministic components while keeping the I(1) trends unchanged. Furthermore, the fact that the trends cancel in the cointegration relations indicates a clear similarity between real house price and real credit cycles, in accordance with the credit view.

Table 4: Test for exclusion of the restricted broken trends

\begin{tabular}{c|ccc|c}
\hline & \multicolumn{3}{|c}{ Univariate $t$-test } & Multivariate $L R$-test \\
\hline & $b t_{90: 01}$ & $b t_{93: 07}$ & $b t_{08: 01}$ & All $b t$ \\
\hline$p$-value & $\mathbf{0 . 1 2 9}$ & 0.030 & $\mathbf{0 . 1 3 3}$ & $\mathbf{0 . 0 7 7}$ \\
\hline
\end{tabular}

Note: The multivariate test is Bartlett-corrected by a correction factor of 1.423 , calculated on the basis of the model with no deterministic terms. I assume a rank of $r=3$.

\footnotetext{
${ }^{21}$ Here, I also tested the same regression on real house prices but without any clear breaks points.
} 
Table 5: I(1) trace test and the unrestricted roots

\begin{tabular}{l|cccccccc}
\hline $\boldsymbol{r}$ & $\mathbf{0}$ & $\mathbf{1}$ & $\mathbf{2}$ & $\mathbf{3}$ & $\mathbf{4}$ & $\mathbf{5}$ & $\mathbf{6}$ & $\mathbf{7}$ \\
$\mathbf{p}-\boldsymbol{r}$ & $\mathbf{7}$ & $\mathbf{6}$ & $\mathbf{5}$ & $\mathbf{4}$ & $\mathbf{3}$ & $\mathbf{2}$ & $\mathbf{1}$ & $\mathbf{0}$ \\
\hline$p_{\text {Bart }}^{*}$ & 0.000 & 0.000 & 0.002 & $\mathbf{0 . 1 3 4}$ & 0.584 & 0.883 & 0.691 & - \\
$\rho_{\max }$ & 0.798 & 0.913 & 0.910 & $\mathbf{0 . 9 0 4}$ & 0.973 & 0.978 & 0.976 & 0.979 \\
\hline
\end{tabular}

Note: $p_{\text {Bart }}^{*}$ is the Bartlett corrected trace test and $\rho_{\max }$ is the largest unrestricted root of the $\Pi$-matrix.

Table 6: General test on the model variables

\begin{tabular}{l|cccccccc}
\hline$p$-values & $h$ & $k$ & $m$ & $y$ & $i_{\text {own }}$ & $i_{3 m}$ & $i_{30 y}$ & $t$ \\
\hline Exclusion & 0.000 & 0.000 & 0.000 & 0.000 & 0.000 & 0.000 & 0.000 & 0.041 \\
Stationarity & 0.000 & 0.000 & 0.000 & 0.000 & $0.000^{*}$ & $0.000^{*}$ & $0.000^{*}$ & - \\
Weekly exogeneity & 0.000 & $\mathbf{0 . 2 7 3}$ & 0.000 & 0.002 & 0.000 & $\mathbf{0 . 0 8 4}$ & $\mathbf{0 . 0 5 0}$ & - \\
Purely adjusting & 0.000 & 0.000 & 0.000 & 0.000 & 0.000 & 0.000 & 0.001 & - \\
\hline
\end{tabular}

Note: ${ }^{*}$ The stationarity tests do not include a trend for the interest rate variables.

The two tests reported in Table 5 suggest a cointegration rank of $r=3$ and, hence, $s_{1}=4 \mathrm{I}(1)$ trends in the model. By contrast, the credit view assumes three common stochastic trends in the model, while the money view assumes only two. To further analyze the composition of the common stochastic trends, Table 6 shows tests for stationarity, excludability, weekly exogeneity, and purely adjusting tendencies of the model variables. As seen, no variables can be excluded from the cointegration space and the stationary and the purely adjusting null hypotheses are rejected for all variables - the latter meaning that no variable is excludable from the common stochastic trends (i.e. have a zero vector in $\alpha_{\perp}$ ). Furthermore, the weekly exogeneity tests indicate that real credit, the short and long-term interest rates (borderline) are weekly exogenous in the model, i.e. weekly explained by the long-run relations. This is equivalent to a unit vector in $\alpha_{\perp}$; thus, in accordance with the credit view, real credit appears to make an important part of the common stochastic trends. The same holds true for both the short and the long-term interest rates, facilitating the idea of a term structure consisting of two common stochastic trends - which runs contrary to the expectation hypothesis. This is one plausible explanation of the unexpected fourth common stochastic trend in the model. Another possibility, if the two theoretical views are not mutually exclusive, is that both money and credit make a stochastic trend in the model. In the end, however, real house prices might also make a common stochastic trend. These possibilities will be analyzed below. From this point forward, I will include the three unrestricted deterministic shifts and assume a rank of $r=3$.

\section{The reduced form VEC analysis}

\subsection{Identification of the VEC representation}

The first step in the empirical analysis is to test for the existence and influence of the hypothetical long-run relations, i.e. the stability and structure of the cointegration rela- 
tions and possible significance of error correction mechanisms.

Table 7: Identifying and non-identifying restrictions on the VEC representation

\begin{tabular}{|c|c|c|c|c|c|}
\hline & \multicolumn{2}{|c|}{ Non-identifying tests } & \multicolumn{3}{|c|}{ Identified system } \\
\hline & MV & $\mathrm{CV}$ & MV & $\mathrm{CV}$ & (TS) \\
\hline \multicolumn{6}{|l|}{$\beta$-matrix } \\
\hline$h$ & $\begin{array}{l}-0.28 \\
(-1.78)\end{array}$ & $\stackrel{1.00}{-}$ & $\begin{array}{l}-0.25 \\
(-5.25)\end{array}$ & $\stackrel{1.00}{-}$ & - \\
\hline$k$ & - & $\begin{array}{c}-1.13 \\
(-25.52)\end{array}$ & - & $\begin{array}{c}-1.18 \\
(-28.53)\end{array}$ & - \\
\hline$m$ & 1.00 & - & 1.00 & - & - \\
\hline$y$ & $\begin{array}{c}-0.99 \\
(-4.3)\end{array}$ & $\begin{array}{c}1.13 \\
(25.52)\end{array}$ & -1.00 & $\begin{array}{c}1.18 \\
(28.53)\end{array}$ & $\begin{array}{l}-4.76 \\
(-2.24)\end{array}$ \\
\hline$i_{\text {own }}$ & $\begin{array}{c}-0.14 \\
(-10.42)\end{array}$ & - & $\begin{array}{c}-0.15 \\
(-12.72)\end{array}$ & - & - \\
\hline$i_{3 m}$ & $\begin{array}{c}0.04 \\
(4.57)\end{array}$ & - & $\begin{array}{c}0.03 \\
(3.93)\end{array}$ & - & $\begin{array}{c}-0.62 \\
(-12.07)\end{array}$ \\
\hline$i_{30 y}$ & $\begin{array}{c}0.10 \\
(12.01)\end{array}$ & $\underset{(7.9)}{0.04}$ & $\begin{array}{c}0.11 \\
(16.01)\end{array}$ & $\begin{array}{l}0.03 \\
(7.06)\end{array}$ & 1.00 \\
\hline$t$ & - & - & - & - & $\begin{array}{l}0.01 \\
(2.4)\end{array}$ \\
\hline \multicolumn{6}{|l|}{$\alpha$-matrix } \\
\hline$\Delta h$ & $\begin{array}{c}0.02 \\
(3.65)\end{array}$ & $\begin{array}{l}-0.02 \\
(-3.96)\end{array}$ & $\begin{array}{l}0.00 \\
(0.78)\end{array}$ & $\begin{array}{l}-0.03 \\
(-5.06)\end{array}$ & $\begin{array}{l}0.00 \\
(-0.16)\end{array}$ \\
\hline$\Delta k$ & $\begin{array}{l}-0.01 \\
(-1.36)\end{array}$ & $\begin{array}{c}0.01 \\
(0.75)\end{array}$ & $\begin{array}{c}0.00 \\
(-0.37)\end{array}$ & $\begin{array}{c}0.01 \\
(0.91)\end{array}$ & $\begin{array}{l}0.00 \\
(-0.64)\end{array}$ \\
\hline$\Delta m$ & $\begin{array}{c}0.00 \\
(-0.10)\end{array}$ & $\begin{array}{l}-0.04 \\
(-4.35)\end{array}$ & $\begin{array}{l}-0.05 \\
(-6.40)\end{array}$ & $\begin{array}{l}-0.05 \\
(-6.39)\end{array}$ & $\begin{array}{l}0.00 \\
(3.88)\end{array}$ \\
\hline$\Delta y$ & $\begin{array}{l}0.03 \\
(3.75)\end{array}$ & $\begin{array}{l}-0.03 \\
(-3.14)\end{array}$ & $\begin{array}{c}0.01 \\
(1.81)\end{array}$ & $\begin{array}{l}-0.02 \\
(-3.07)\end{array}$ & $\begin{array}{l}0.00 \\
(-1.54)\end{array}$ \\
\hline$\Delta i_{\text {own }}$ & $\begin{array}{l}0.50 \\
(5.44)\end{array}$ & $\begin{array}{c}-0.30 \\
(-3.6)\end{array}$ & $\begin{array}{l}0.49 \\
(6.99)\end{array}$ & $\begin{array}{l}-0.08 \\
(-1.02)\end{array}$ & $\begin{array}{l}-0.06 \\
(-7.56)\end{array}$ \\
\hline$\Delta i_{3 m}$ & $\begin{array}{l}-0.52 \\
(-1.21)\end{array}$ & $\begin{array}{c}0.67 \\
(1.76)\end{array}$ & $\begin{array}{l}0.19 \\
(0.59)\end{array}$ & $\begin{array}{l}0.57 \\
(1.67)\end{array}$ & $\begin{array}{l}0.02 \\
(0.61)\end{array}$ \\
\hline$\Delta i_{30 y}$ & $\begin{array}{c}0.86 \\
(1.68) \\
\end{array}$ & $\begin{array}{r}-1.43 \\
(-3.13)\end{array}$ & $\begin{array}{l}0.57 \\
(1.47) \\
\end{array}$ & $\begin{array}{l}-0.79 \\
(-1.95) \\
\end{array}$ & $\begin{array}{l}-0.13 \\
(-2.91)\end{array}$ \\
\hline$p$-value & 0.049 & 0.150 & $\ldots-\cdots$ & -0.159 & $-\ldots-$. \\
\hline
\end{tabular}

Note: $t$-values are shown in parenthesis. Significant coefficients on a $5 \%$ level are marked bold.

The left-most columns of Table 7 shows individual non-identifying tests of the money and credit view relations: (11) and (12), in each case with the remaining two relations left unrestricted. The money view relation (MV) is found to be borderline significant and has the expected significant signs with respect to real GDP, opportunity costs and real house prices (borderline). These results are fairly in line with earlier literature by Greiber and Setzer (2007), and others, though with a higher output elasticity (close to unity), a lower elasticity on real house prices (the wealth effect), and opportunity costs dominated by the long-term interest rate (typically not included earlier). Considering the $\alpha$-matrix, real house prices, real GDP and the own rate on money all error correct, which is also in accordance with the findings by Greiber and Setzer (2007). Thus, and as expected, excess liquidity has a positive effect on real house prices and real GDP. The error correction coefficient of money is found insignificant, which is, however, somewhat critical to the interpretation of the relation. ${ }^{22}$

\footnotetext{
${ }^{22}$ When restricting money to zero in the remaining two relations, I find that money error corrects, while the relation is still significant and does not change notably.
} 
Turning to the credit view relation (CV), this is also found to be significant and stable with the expected signs on all variables. As a result, when correcting for the cost of financing, leverage and real house prices share the same long-run cycles. Real house prices, real GDP and the mortgage rate all error correct, which indicates that real house prices are determined by the mortgage rate and the leverage of the economy. As indicated by the tests for weekly exogeneity, real credit does not error correct, supporting the idea that house price bubbles are caused by real credit cycles, and not the other way around. These findings are generally in line with earlier related literature. Goodhart and Hofmann (2007) find a similar long-run relation in the US, however, without the unity restriction between real GDP and real credit, and with a higher degree of elasticity for real house prices with respect to real GDP and real credit. These differences may be due to a different sample period and frequency, as Goodhart and Hofmann (2007) analysis includes quarterly data from 1980 to 1998, and hence, importantly, they do not cover the period of the global financial crisis. Another explanation may lie in the fact that they disregard the existence of $\mathrm{I}(2)$ trends in the data. My results are quite in line with the results by Gimeno and Martínez-Carrascal (2010), analyzing the Spanish economy from 1984 to 2009, and they, too, find significant error correction of house prices.

Thus far, both views have been shown to be individually important for real house prices and real GDP. Interestingly, however, the $\alpha$-coefficients are strikingly familiar, which may indicate some degree of multicollinearity between the non-identified relations. To analyze this possibility, I perform a multivariate test for both restrictions in the model. This is accepted with a $p$-value of 0.165 , which means that I cannot reject the null hypothesis that both cointegration vectors are concurrently present in the model, i.e. they do not cancel each other out. From this result, I further identify the full model including both restrictions (with an additional unity restriction on the money-output elasticity), plus a third relation for the term structure of interest rates (TS). This model is identified by a $p$-value of 0.159 , as shown in the right-most columns of Table 7 . Comparing the identified system with the non-identifying tests, the $\beta$-parameters are almost unaltered, while the $\alpha$-parameters related to the money view relation have changed substantially. Here, the error correction mechanisms of real house prices and real GDP have become insignificant. Thus, even though the non-identifying tests support both theoretical views, the full model indicates that the credit view dominates the money view.

Assuming a positive credit shock in the economy, which entails a disequilibrium of the credit view cointegration relation, the error correction mechanisms of real house prices and real GDP result in an economic boom and house price bubble scenario. This result is generally in accordance with the asset boom-bust model proposed by Allen and Gale (2000). Moreover, the indication of slight multicollinearity and changing 
error correction coefficients might indicate that excess liquidity and excess credit growth are somehow related, as discussed in section 3.3. Considering the error correction of money to the credit view cointegration relation, the results suggest that credit growth leads to excess liquidity, and not the other way around. This also provides a plausible explanation for the multifaceted results seen in earlier related literature.

It is also worth noting that the weekly exogeneity of real credit and the short-term interest rate found earlier are seen as insignificant rows in the $\alpha$-matrix. The third longrun relation, however, suggest that the long-term interest rate are explained by the short-term interest rate and the output gab. This conflicts somewhat with the expectation hypothesis, but the term structure only makes a single common stochastic trend in the model. Hence, the origin of the fourth common stochastic trend is still unknown.

\subsection{Constancy of the parameter regime}

With an identified model, I further test the stability of the model. Figures C.1 and C.2 in Appendix $\mathrm{C}$ show tests for constancy of the log-likelihood and the identified $\beta$ matrix. Here, the $\beta$-matrix is found to be stable throughout the sample period, while this is not the case for the log-likelihood - even when the short-run parameters are excluded (the $R$-form). Together, this might indicate some inconstancy related to the $\alpha$-matrix. Assuming a constant $\beta$-matrix, Figure C.3 in Appendix C therefore illustrates recursive estimations of the $\alpha$-parameters related to the long-run relations ( $R$-form), i.e. (MV) and (CV) from the identified model ( $\beta$ held constant). Especially considering the backward recursive estimations, there seems to be a general structural change in the error correction mechanisms around year 2000, which is consistent with the loglikelihood constancy test. When testing for an additional $R$-form cointegration term from 2000:01 and onwards this term is also found to be significant with a $p$-value of 0.004, hence, I cannot reject that the error correction mechanisms are time-varying. ${ }^{23}$ To analyze the implications of this structural change, I further split the sample period and estimate two submodels on data before and after 2000, with the identified $\beta$-matrix from the right-most columns of Table 7 held constant. This estimation is shown in Table 8.

Considering the two submodels, both real house prices and real GDP error correct significantly to the money view relation only from year 2000 and onwards. More or less the opposite holds true for the credit view relation, which again illustrates the interdependence of credit growth and excess liquidity. As another interesting result, the short-term interest rate plays an important role as a driving variable in the early period, while this role shifts to the long-term interest rate in the latter period.

\footnotetext{
${ }^{23}$ I test the significants of the additional term; $I(t \geqq 2000: 01) \alpha \beta^{\prime} R_{1 t}$, where $I(\cdot)$ is equal to zero before 2000 and equal to unity from year 2000 and onwards. Each of the individual cointegration relations are also found significantly different before and after year 2000 .
} 
Table 8: The error correction mechanisms estimated on subsamples.

\begin{tabular}{|c|c|c|c|c|c|c|}
\hline \multirow[b]{2}{*}{$\alpha$-matrix } & \multicolumn{3}{|c|}{ Before 2000:01 } & \multicolumn{3}{|c|}{ From 2000:01 and onwards } \\
\hline & MV & $\mathrm{CV}$ & (TS) & MV & CV & (TS) \\
\hline$\Delta h$ & $\begin{array}{l}-0.01 \\
(-0.84)\end{array}$ & $\begin{array}{l}-0.03 \\
(-3.23)\end{array}$ & $\begin{array}{l}0.00 \\
(0.99)\end{array}$ & $\begin{array}{l}0.03 \\
(2.23)\end{array}$ & $\begin{array}{l}-0.01 \\
(-1.00)\end{array}$ & $\begin{array}{c}0.00 \\
(-1.13)\end{array}$ \\
\hline$\Delta k$ & $\begin{array}{l}0.00 \\
(0.30)\end{array}$ & $\begin{array}{l}0.01 \\
(0.67)\end{array}$ & $\begin{array}{c}0.00 \\
(-0.80)\end{array}$ & $\begin{array}{c}0.00 \\
(0.14)\end{array}$ & $\begin{array}{l}0.01 \\
(0.83)\end{array}$ & $\begin{array}{c}0.00 \\
(-0.20)\end{array}$ \\
\hline$\Delta m$ & $\begin{array}{l}-0.04 \\
(-3.90)\end{array}$ & $\begin{array}{l}-0.03 \\
(-1.97)\end{array}$ & $\begin{array}{l}0.00 \\
(2.25)\end{array}$ & $\begin{array}{l}-0.05 \\
(-2.46)\end{array}$ & $\begin{array}{l}-0.06 \\
(-3.89)\end{array}$ & $\begin{array}{c}0.00 \\
(1.91)\end{array}$ \\
\hline$\Delta y$ & $\begin{array}{c}0.00 \\
(0.29)\end{array}$ & $\begin{array}{l}-0.03 \\
(-1.39)\end{array}$ & $\begin{array}{l}0.00 \\
(0.44)\end{array}$ & $\begin{array}{l}0.04 \\
(3.05)\end{array}$ & $\begin{array}{l}-0.01 \\
(-1.25)\end{array}$ & $\begin{array}{c}0.00 \\
(-3.11)\end{array}$ \\
\hline$\Delta i_{\text {own }}$ & $\begin{array}{l}0.48 \\
(3.96)\end{array}$ & $\begin{array}{l}0.12 \\
(0.68)\end{array}$ & $\begin{array}{l}-0.06 \\
(-4.38)\end{array}$ & $\begin{array}{l}0.82 \\
(5.40)\end{array}$ & $\begin{array}{l}0.01 \\
(0.07)\end{array}$ & $\begin{array}{l}-0.08 \\
(-6.08)\end{array}$ \\
\hline$\Delta i_{3 m}$ & $\begin{array}{c}0.30 \\
(0.46)\end{array}$ & $\begin{array}{l}0.15 \\
(0.16)\end{array}$ & $\begin{array}{l}-0.01 \\
(-0.17)\end{array}$ & $\begin{array}{l}1.23 \\
(2.02)\end{array}$ & $\begin{array}{l}1.08 \\
(2.02)\end{array}$ & $\begin{array}{l}-0.03 \\
(-0.51)\end{array}$ \\
\hline$\Delta i_{30 y}$ & $\begin{array}{c}1.49 \\
(1.79) \\
\end{array}$ & $\begin{array}{l}-1.74 \\
(-1.43) \\
\end{array}$ & $\begin{array}{l}-0.20 \\
(-2.25) \\
\end{array}$ & $\begin{array}{c}0.56 \\
(0.78) \\
\end{array}$ & $\begin{array}{l}-0.44 \\
(-0.70) \\
\end{array}$ & $\begin{array}{l}-0.11 \\
(-1.84) \\
\end{array}$ \\
\hline
\end{tabular}

Note: The $\beta$-matrix is assumed constant as given in the right-most columns of Table 7. $t$-values are shown in parenthesis. Significant coefficients on a 5\% level are marked bold.

These results are more or less in line with earlier ideas that mechanisms of financial instability are time-varying and dependent on the state of the business cycle or the structural policy and financial market regime. Earlier empirical literature points to various explanations and findings. Non-linear VAR models by e.g. Kaufmann and Valderrama (2007) support the general idea of switching economic regimes and varying effects in relation to asset price inflation. Others point to clear historical break coinciding with reforms of financial deregulation. For example, Goodhart and Hofmann (2008) analyze 17 industrialized countries and find stronger relations between house prices and monetary and credit variables from 1985 and onwards, especially when house prices are booming. Oikarinen (2009) points to a similar break in Finland following the country's period of financial liberalization in the late 1980s. Yet a third plausible explanation is given by Giese and Tuxen (2007), who suggest that a global expansionary monetary policy pursued by the US beginning in 2001 - found in their model as an exogenous positive shift in the money supply-demand relation - had important implications for global house prices in the following years.

The present results might be explained by a combination of shifting economic regimes, deregulated financial markets - e.g. The Gramm-Leach-Bliley Act of 1999 - and a period of expansionary monetary policy at a time where both housing and credit markets experience a prolonged boom period. Even though the credit view dominates in a linear setup, allowing of structural changes in the error correction mechanisms suggest time dependent effects of excess liquidity on house price bubbles and financial instability. Hence, time-varying mechanisms might also explain the various results seen earlier in the literature. 


\subsection{The long-run relations}

Figure 3 illustrate the long-run relations; (MV) and (CV) from the identified model on standard form and $R$-form. Considering the money view relation, the standard form does not systematically deviate from the $R$-form, implying that the relation is, as expected, unaffected by the unrestricted shifts. This is, however, not the case for the credit view relation. Here, the unrestricted shifts are seen as clear level deviations between the two, especially before 1990:01 and after the onset of the global financial crisis in 2008:01. Even though interest rate adjusted leverage and real house prices evolve similarly with respect to the cycle break points and growth rates, these level deviations indicate that the ratio between the two is not constant between the different regimes.

Figure 3: The long-run relations for the two theoretical perspectives
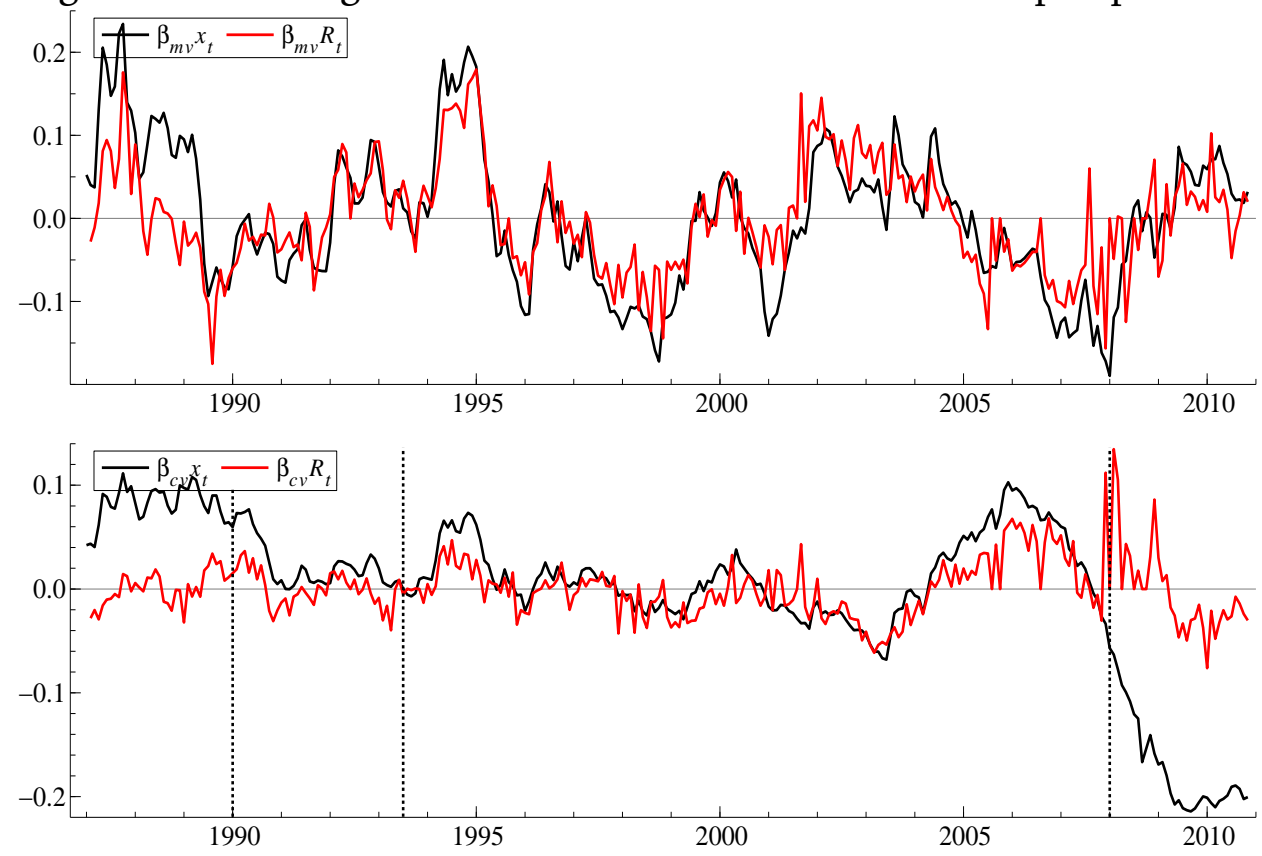

Note: In the upper graph excess liquidity is increasing with the axis, while in the lower graph excess leverage is decreasing with the axis. The $\beta x_{t}$ s are scaled to mach means.

Considering the standard cointegration relations in the years preceding the global financial crisis, some symmetry is seen in the relations, which also points to the earlier results of slight multicollinearity. The hypothetical exogenous credit boom resulting from the deterministic shift in 1993:07 seems to be followed by a quite stable period of evolution in the credit view relation until 2005. At least until year 2000, this stability is sustained by error correction mechanisms of real house prices and real GDP, which indicates that the credit boom has spilled over to the goods and housing market. In the period after the dot-com crash (2001 to 2005) - in which excess liquidity is also found to be important - the relations indicate both excess liquidity and excess leverage in the economy. Consistent with earlier findings and conclusions by e.g. Giese and Tuxen (2007), this is possibly a result of the expansionary monetary policy pursued 
throughout this period. In contrast, the period from 2005 until the global financial crisis is dominated by a lack of liquidity and relatively low leverage, possibly as a result of the contractionary monetary policy and accelerating house price inflation.

In summary, the relations seem consistent concerning the onset of a house price bubble in the mid-1990s, a price acceleration after year 2000, and a bubble burst around 2005. However, the fact is that the real house price boom did not slow down until the beginning of 2006, while the actual crash did not occur until the beginning of 2007 . Hence, there is a gap of about two years from the point where both theoretical relations predict a real house price crash until such a crash actually occurred. As a result of this "unexplained" house price inflation, both relations result in large disequilibriums throughout this period. In this respect, the global financial crisis entails a fast contraction and even an overshooting tendency. Considering a policy perspective, it seems the Federal Reserve did try to hinder further house price inflation from 2005, but with a quite limited or lagged effect.

\section{The structural VMA analysis}

The reduced form VEC representation analyzed in the previous section allowed me to identify cointegration vectors and analyze the long-run relations between variables. To gain greater insight into the dynamics of the system I now turn to the structural VMA representation.

Here, I maintain the previous restrictions from the VEC representation and disregarding the non-constancy specification from Section 6.2, fully understanding that I hereby consider the average effects of time-varying mechanisms. The structural VMA representation has to be identified, which demands assumptions about the interpretation and causality ordering of shocks in the model (see Section 2.2 and footnote 8 on page 8 for details). Importantly, I have found that the term structure only makes up one common stochastic trend in the model (given (TS) in Table 7), and that real credit and the short-term interest rate are essential to the common stochastic trends. Using these finding and the methods discussed in Section 2.2, I will analyze how the variables are affected by the permanent shocks using three different types of long-run structural identification schemes, illustrated by the long-run $\tilde{C}$-restriction shown in Table 9:24

1. First of all, I analyze a standard identification. As is commonplace in macroeconomic literature, the first permanent shock is assumed to be a supply shock $\left(u_{p 1[y]}\right)$, meaning that in the long run GDP does not respond to other shocks. Furthermore, it is often assumed that the central bank policy determines the liquidity

\footnotetext{
${ }^{24}$ The identification and analysis of permanent shocks are independent of identification of temporary shocks, why these are left unrestricted.
} 
through the short-term interest rate; thus, I assume a second permanent shock related to the short-term interest rate $\left(u_{p 2\left[l i q_{i}\right]}\right)$. The third permanent shock is assumed to be a real credit shock $\left(u_{p 3[k]}\right)$.

2. Secondly, and more in line with the theory of financial instability and the focus of this paper, I consider a non-standard identification in which real credit and liquidity shocks are allowed to influence real GDP in the long run. Hence, I assume that the first permanent shock is related to real credit $\left(u_{p 1[k]}\right)$, while the second is related to liquidity $\left(u_{p 2\left[i q_{m}\right]}\right)$ - here restricted to the real money supply (not the interest rate). As for the third permanent shock, I assume a real GDP shock $\left(u_{p 3[y]}\right)$.

3. As a last robustness check, I will try to separate standard interest rate effects from the mechanisms of liquidity shock given by the money view. In the above nonstandard identification 2 I will enforce an interest rate shock $\left(u_{p 2[i]}\right)$ before the liquidity shock. While somewhat unrealistic, the third shock is interpreted as a liquidity shock related to real money but unrelated to the short-term interest rate $\left(u_{p 3\left[i q_{m}\right]}\right)$.

Table 9: Three types of identifying restrictions on the $\tilde{C}$-matrix

\begin{tabular}{|c|c|c|c|c|c|c|c|c|c|c|c|c|}
\hline & \multicolumn{4}{|c|}{ 1. Standard } & \multicolumn{4}{|c|}{ 2. Non-standard } & \multicolumn{4}{|c|}{ 3. Robustness check } \\
\hline & $u_{p 1[y]}$ & $u_{p 2\left[l i q_{i}\right]}$ & $u_{p 3[k]}$ & $u_{p 4}$ & $u_{p 1[k]}$ & $u_{p 2\left[l i q_{m}\right.}$ & $u_{p 3[y]}$ & $u_{p 4}$ & $u_{p 1[k]}$ & $u_{p 2[i]}$ & $u_{p 3\left[l i q_{m}\right]}$ & $u_{p 4}$ \\
\hline$h_{t}$ & $*$ & $*$ & $*$ & $*$ & $*$ & $*$ & $*$ & $*$ & $*$ & $*$ & $*$ & $*$ \\
\hline$k_{t}$ & $*$ & * & * & 0 & * & 0 & 0 & 0 & * & 0 & 0 & 0 \\
\hline$m_{t}$ & * & * & * & * & * & $*$ & 0 & 0 & $*$ & $*$ & $*$ & 0 \\
\hline$y_{t}$ & * & 0 & 0 & 0 & $*$ & $*$ & $*$ & 0 & $*$ & $*$ & * & $*$ \\
\hline$i_{\text {own }, t}$ & * & * & * & * & * & $*$ & $*$ & $*$ & * & $*$ & $*$ & $*$ \\
\hline$i_{3 m, t}$ & $*$ & * & 0 & 0 & $*$ & $*$ & $*$ & $*$ & * & $*$ & 0 & 0 \\
\hline$i_{30 y, t}$ & $*$ & $*$ & $*$ & $*$ & $*$ & $*$ & $*$ & $*$ & $*$ & $*$ & $*$ & $*$ \\
\hline
\end{tabular}

Note: $*$ indicates unrestricted parameters and the last three columns of the $\tilde{C}$-matrix are generally restricted to zero.

For the standard identification scheme, Figure 4 shows 120 month (10 years) responses from one standard deviation in the permanent structural shocks. To highlight their significance, the gray bands show $95 \%$ confidence bounds calculated as boot strap simulations with 500 replications. ${ }^{25}$ First of all, supply shocks only have a significant effect on real GDP and real credit, which is somewhat unexpected. Secondly, as expected, the negative restricted interest rate shocks is related to increases in real money, which supports the interpretation that it is a liquidity shock. Thirdly, while both liquidity and real credit shocks have a positive effect on real house prices in the long run, neither are allowed to have a long-run effect on real GDP. These results are quite in line with the

\footnotetext{
${ }^{25}$ These are calculated by parametric bootstrapping in the program Structural VAR by Anders Warne.
} 
proposed hypotheses.

Figure 4: Structural IR functions, standard identification

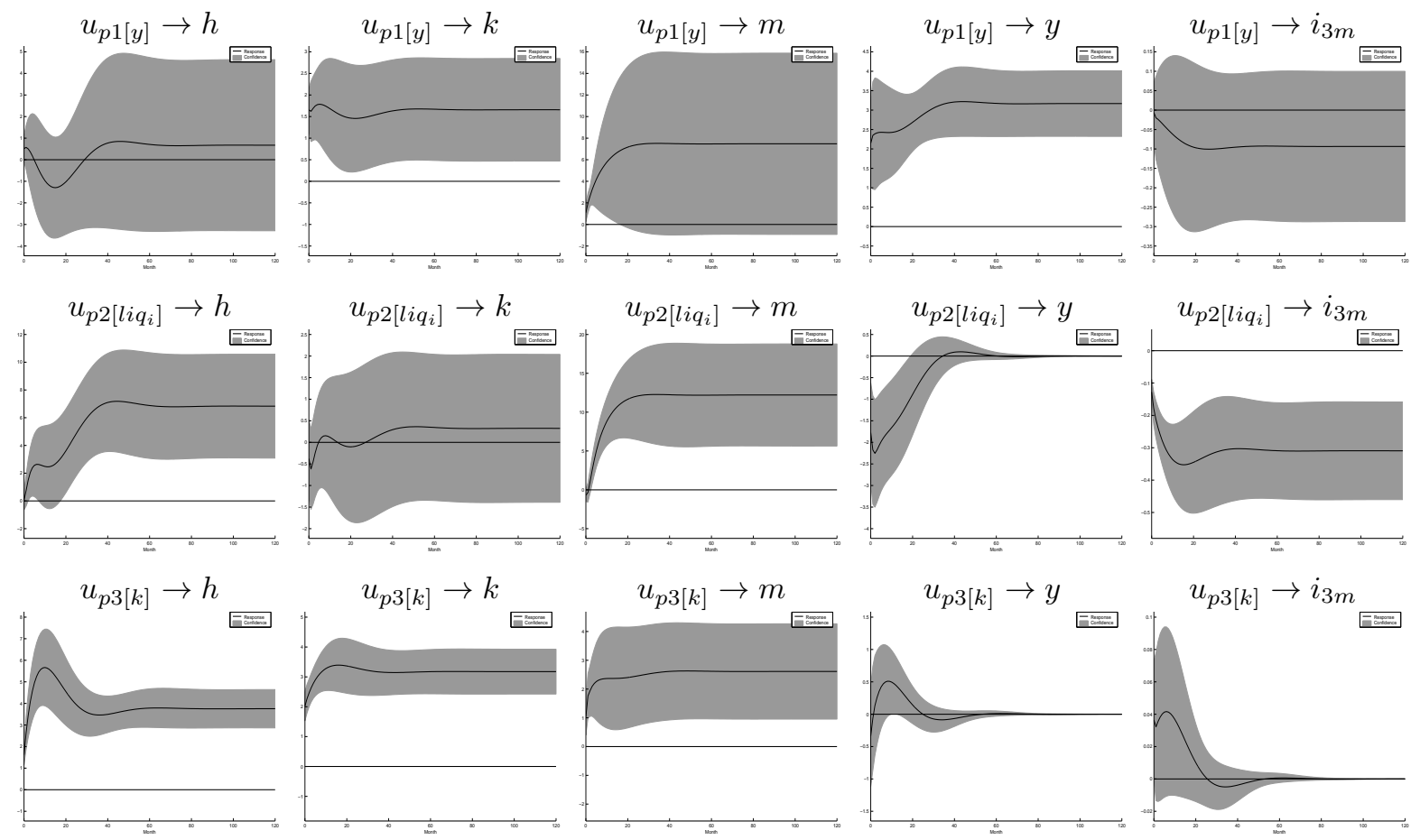

Note: $i$ ) The horizon is 120 months (10 years) ii) IR to a positive structural shock of one std. iii) The gray bands are $95 \%$ confidence bounds calculated by bootstrap-simulation with 500 replications.

Figure 5: Structural IR functions, non-standard identification

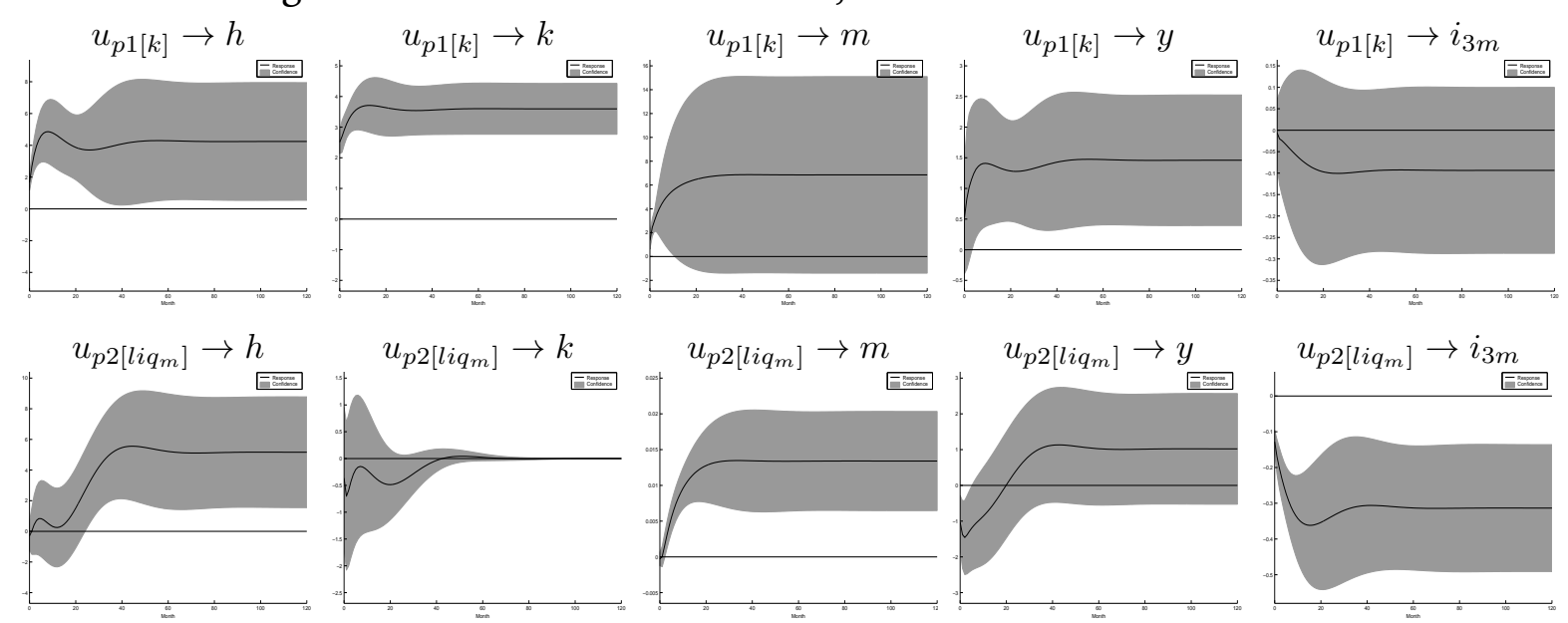

Note: $i)$ The horizon is 120 months (10 years) ii) IR to a positive structural shock of one std. iii) The gray bands are $95 \%$ confidence bounds calculated by bootstrap-simulation with 500 replications.

To further analyze the hypothetical effects on real GDP, the IR functions of the nonstandard identification are shown in Figure 5. As seen here, the real credit shocks now have a long-run positive effect on real GDP and real house prices, in accordance with the credit view and the results of the VEC representation. Compared to the effect found in the standard identification, the effects on real house prices seem somewhat smaller, though still significant. The effect of liquidity shocks on house prices also seems robust 
to this reidentification, while the effect on real GDP is found to be insignificant. This results are concur with those of the VEC representation, as well as with controversial macroeconomic theories positing that liquidity and monetary policy do not affect real GDP in the long run.

Figure 6: Structural IR functions, robustness check
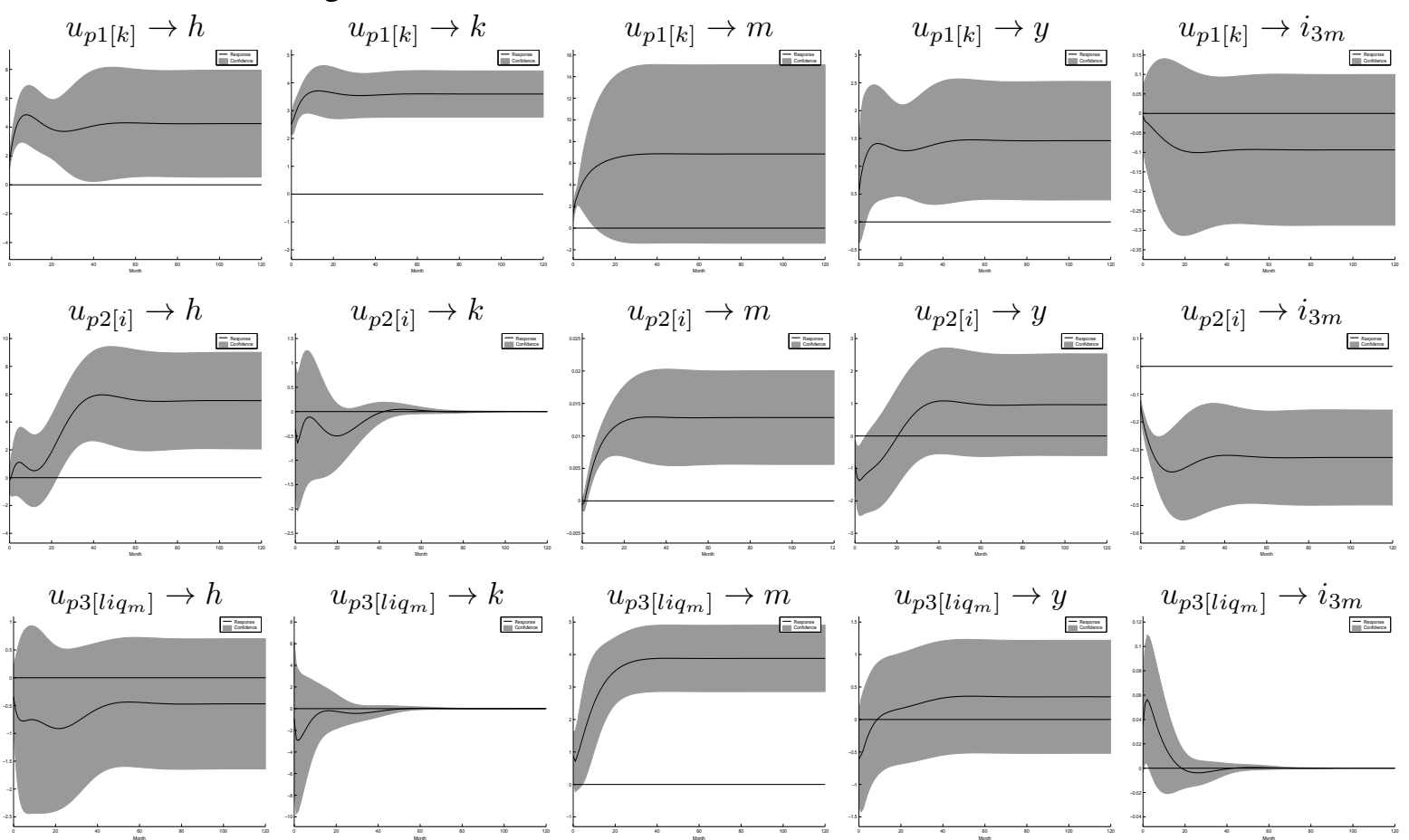

Note: $i$ ) The horizon is 120 months (10 years) ii) IR to a positive structural shock of one std. iii) The gray bands are $95 \%$ confidence bounds calculated by bootstrap-simulation with 500 replications.

As a critical point, there is no guarantee that the observed effects of the liquidity shocks are not simply the result of standard interest rate effects related to the higher costs of home financing, etc. To further analyze this possibility, Figure 6 illustrates the IR functions of the robustness identification scheme. As seen here, the effects of real credit shocks are robust to the reidentification, while liquidity shocks now have an insignificant effect on real house prices. More over, the previous interpreted liquidity effects now seem related to the interest rate shocks, given the similar effect on real house prices, real GDP, etc. As a result, it is either not possible to separate short-term interest rate shocks from liquidity shocks, or only the standard interest rate effects of the lower cost of home financing is relevant for real house prices in the long run.

The general result of the IR analysis is that credit shocks have a positive effect on real house prices and real GDP in the long run, which are quite robust to different identification schemes. This supports the earlier findings from the VEC representation. In contrast, the effects of liquidity shocks are heavily dependent on the identifying assumptions and are generally difficult to separate from standard interest rate effects. However, when a combination of liquidity shocks and negative short-term interest rates 
are analyzed, the results suggest a positive effect on house prices. Hence, expansionary monetary policy has a positive effect on real house price, which also underlines the influence of such policies in the period following the dot-com crash (2001 to 2005).

These results are not all in accordance with earlier findings. Greiber and Setzer (2007) use another type of specification, Choleski decomposition, and find that liquidity shocks generally have significant effects on real house prices. They further include credit shocks in their robustness analysis but find that real house prices are more or less unaffected by credit shocks. This result is also supported by Adalid and Detken (2007) considering a cross section analysis including 18 OECD countries. In contrast, in their factor augmented VAR analysis of the G-7 countries, Helbling et al. (2010) find that credit shocks have a large influence on G-7 real GDP - particulary in the event of shocks from the US economy and during crisis periods. In the end, Goodhart and Hofmann (2008) analyze a panel VAR model of 17 industrialized countries from 1970 to 2006 and find that both liquidity and credit shocks affect real GDP and house prices positively.

\section{Concluding remarks}

In this paper I have analyzed the macroeconomic mechanisms of financial instability within a seven variable I(1) CVAR model based on US data. Considering the two theoretical perspectives - the money view and the credit view - the aim has been to analyze the relative importance of excess liquidity versus credit cycles in relation to house price bubbles and economic booms.

In order to achieve a well specified I(1) CVAR model, I have added deterministic shifts to replace overly persistent I(2) or broken trends in real credit and real house prices. According to the credit view, these structural components are related to a series of important structural policy changes from the 1980s. Furthermore, by imposing separate, non-identifying long-run restrictions on the cointegration vectors reflecting the two views, I have analyzed house prices in relation to both credit cycles and excess liquidity. From these non-identifying tests, both long-run relations were found to be significant and stable with the expected parameter values and error correcting mechanisms of real house prices and real GDP. When identifying the full system, however, the effects of the money view were generally dominated by the effects of the credit view, also indicating some related explanatory power of excess liquidity and credit growth. The general domination of the money view was further questioned when analyzing the stability of the error correction mechanisms. Here, the results suggested time-varying error correction mechanisms, and excess liquidity was fount to be important in the period after year 2000 .

In regards to the global financial crisis, a deterministic shift in 1993 - representing 
the financial innovation of subprime mortgages - seems to have initiated a prolonged booming credit cycle. This in turn resulted in an economic boom and housing bubble scenario, which was further fuelled by expansionary monetary policy and excess liquidity following the dot-com crash. While increasing financial instability is explained by the credit view relation from the mid-1990s, and by the money view relation from the early 2000s, the last two years of accelerating house price inflation prior to the crisis (2005 to 2007) is generally unexplained by the two long-run relations.

Further, considering the mechanisms from another perspective, I have estimated the effects of credit and liquidity shocks in the economy, using different identification schemes within a structural VMA representation. Here, I also find support for the credit view; credit shocks generally were found to have a robust positive long-run effect on real house prices and real GDP. For the money view, the house price response to compounded liquidity and interest rate policy shocks was generally found to be positive. However, further analysis of the separate liquidity and interest rate shocks only supported the importance of standard interest rate effects, meaning varying home financing costs.

Given these results, it is not surprising that earlier empirical analyses tend to support both the credit view and the money view when the hypotheses are tested independently and based on different sample periods etc. My empirical study, which accounts for both hypotheses in the same model, allows me to test each hypothesis as conditioned on the existence of the other. These conditions are found to be important, as the explanatory power of excess liquidity and credit growth seem quite related. The results also suggest time-varying effect of financial instability, in which the credit view dominates when analyzing the entire sample, while the money view dominates the post dot-com crash period. Hence, depending on the sample period, one might find different results. In the end, the separation of liquidity effects from standard interest rate effects is found to be questionable but very important for interpretation of the liquidity effect.

In summary, my results suggest that capital structures and the overall leverage of the economy are essential to financial instability, while excess liquidity only has a less robust effect in certain periods. Meanwhile, credit and liquidity are found to be closely related, which might explain the varying results of the preciously mentioned literature. In relation to the global financial crisis, the analysis indicates that the expansionary monetary policy in the post dot-com period (2001 to 2005) had some financial destabilizing effect. More importantly, however, deregulation and innovation of the financial markets resulted in a high rate of credit growth and house price inflation from the mid-1990s until the onset of the global financial crisis. As a result, the analysis generally suggests a more direct focus on leverage and house price cycles, both in terms of monetary policy and especially in terms of structural policy. 


\section{References}

Adalid, R. and C. Detken (2007). Liquidity shocks and asset price boom/bust cycles. ECB-Working paper.

Allen, F. and D. Gale (2000, January). Bubbles and Crises. The Economic Journal 110(460), 236-255.

Atanasova, C. (2003). Credit market imperfections and business cycle dynamics: A nonlinear approach. Studies in Nonlinear Dynamics and Econometrics 7(4).

Borio, C. E. V. and P. W. Lowe (2004). Securing sustainable price stability: should credit come back from the wilderness? BIS-working papers (157).

Carlson, J. B. and B. D. Keen (1996). MZM: A Monetary Aggregate for the 1990s? Economic Review: Journal of Federal Reserve Bank of Cleveland Q II, 15-23.

Chomsisengphet, S. and A. Pennington-Cross (2006). The evolution of the subprime mortgage market. Review: Journal of Federal Reserve Bank of St. Louis (Jan).

Claessens, S., M. A. Kose, and M. E. Terrones (2011). How Do Business and Financial Cycles Interact? IMF Working Paper (88).

Congdon, T. (2006). Money and asset prices in boom and bust. Institute of Economic Affairs.

Cooper, G. (2008). The Origin of Financial Crises: Central Banks, Credit Bubbles and the Efficient Market Fallacy. Harriman House LTD.

Ferri, P. and H. P. Minsky (1992). Market processes and thwarting systems. Structural Change and Economic Dynamics 3(1), 79-91.

Fisher, I. (1933). The debt-deflation theory of great depressions. Econometrica: Journal of the Econometric Society 1(4), 337-357.

Friedman, M. (1956). The Quantity Theory of Money - a Restatement. In Studies in the Quantity Theory of Money. Univ. Chicago Press.

Gerlach, S. and W. Peng (2005, February). Bank lending and property prices in Hong Kong. Journal of Banking \& Finance 29(2), 461-481.

Giese, J. V. and C. K. Tuxen (2007). Global liquidity and asset prices in a cointegrated VAR. Unpublished working paper. 
Gimeno, R. and C. Martínez-Carrascal (2010, August). The relationship between house prices and house purchase loans: The Spanish case. Journal of Banking \& Finance 34(8), 1849-1855.

Goodhart, C. and B. Hofmann (2007). House Prices and the Macroeconomy: Implications for Banking and Price Stability. Oxford University Press.

Goodhart, C. and B. Hofmann (2008). House prices, money, credit, and the macroeconomy. Oxford Review of Economic Policy 24(1), 180 - 205.

Gorton, G. (2008). The panic of 2007. NBER Working Paper (14358).

Greiber, C. and W. Lemke (2005). Money demand and macroeconomic uncertainty. Deutsche Bundesbank WP (26).

Greiber, C. and R. Setzer (2007). Money and housing: evidence for the euro area and the US. Deutsche Bundesbank WP (12).

Helbling, T., R. Huidrom, M. Kose, and C. Otrok (2010). Do Credit Shocks Matter? A Global Perspective. IMF Working Paper (261).

Juselius, K. (2007). The Cointegrated VAR Model: Methodology and Applications. Oxford University Press.

Kaufmann, S. and M. T. Valderrama (2007). The role of credit aggregates and asset prices in the transmission mechanism: a comparison between the euro area and the US. ECB-Working paper (816).

Keynes, J. M. (1936). The general theory of employment, interest and money. Great Minds Series.

Kiyotaki, N. and J. Moore (1997). Credit cycles. Journal of political economy 105(2), 211-248.

Lütkepohl, H. and M. Krätzig (2004). Applied time series econometrics. Cambridge University Press.

Meltzer, A. H. (1995). Monetary, credit and (other) transmission processes: a monetarist perspective. The Journal of Economic Perspectives 9(4), 49-72.

Minsky, H. P. (1993). The Financial Instability Hypothesis. Handbook of Radical Political Economy (74).

Modigliani, F. and M. H. Miller (1958). The cost of capital, corporation finance and the theory of investment. The American Economic Review 48(3), 261-297. 
Oikarinen, E. (2009). Interaction between housing prices and household borrowing: The Finnish case. Journal of Banking \& Finance 33(4), 747-756.

Reinhart, C. and K. Rogoff (2009). This time is different: Eight centuries of financial folly. Princeton University Press.

Temkin, K., J. E. H. Johnson, and D. Levy (2002). Subprime Market, The Role of GSEs, and Risk-based Pricing. The Urban Institude. 


\section{Appendix A: Data sources and data construction}

The data of the model consist of the following seven variables, where for the nominalto-real calculations I use the CPI, all items city average:

Table A.1: The variables of the model

\begin{tabular}{|c|c|c|}
\hline Ticker & Description & Source \\
\hline$h$ & Real house prices $(\log )$ & $\begin{array}{l}\text { House Prices, Freddie Mac, national, index } \\
\text { (quarterly). }\end{array}$ \\
\hline$k$ & Real credit (log) & $\begin{array}{l}\text { Debt Outstanding, domestic nonfinancial sec- } \\
\text { tors, total, SA, USD (quarterly). }\end{array}$ \\
\hline$m$ & The real quantity of money, M2M (log) & $\begin{array}{l}\text { y M2, SA, USD, excluding small } \\
\text { s. }\end{array}$ \\
\hline$y$ & Real GDP (log) & $\begin{array}{l}\text { GDP, overall, total, CP, AR, SA, USD (quar- } \\
\text { terly). }\end{array}$ \\
\hline & $\mathrm{T}$ & M2M Money St \\
\hline & Three mon & ury bills, bid, 3 month, yield, average. \\
\hline$i_{30 y}$ & 30 year nominal fixed mortgage rate & Freddie Mac. \\
\hline
\end{tabular}

Table A.2: Data for Chow-Lin interpolation

\begin{tabular}{l|ll}
\hline Ticker & Quarterly series & Monthly series (source) \\
\hline$h$ & Real house prices (log) & $\begin{array}{l}\text { House Prices, S\&P Case-Shiller, composite-10, } \\
\text { index. }\end{array}$ \\
$k$ & Real credit (log) & $\begin{array}{l}\text { Consumer credit, total, SA, USD. } \\
\text { i) US national unemployment rate, ii) BIS, } \\
\text { real narrow effective exchange rate, index, av- } \\
\text { erage, iii) US industrial production. }\end{array}$ \\
\hline
\end{tabular}

\section{Appendix B: Model specification}

\section{A univariate Markov switching process}

Table B.1: Regime classification based on smoothed probabilities

\begin{tabular}{l|cc}
\hline Regime 0 & Months & Average probability \\
\hline 1990:01 - 1993:06 & 42 & 0.964 \\
2008:01 - 2008:07 & 7 & 0.906 \\
2009.01 - 2010:06 & 18 & 0.989 \\
\hline Regime 1 & & \\
\hline 1987:01 - 1989:12 & 88 & 0.992 \\
1993:07 - 2007:12 & 174 & 0.984 \\
2008:08 - 2008:12 & 5 & 0.862 \\
\hline
\end{tabular}

Note: Regime 0 totally has 67 months (20.06\%) with an average duration of 22.33 months. Regime 1 totally has 267 months (79.94\%) with an average duration of 89.00 months. 


\section{Appendix C: The VEC analysis}

\section{Test for parameter constancy}

Figure C.1: Test for constancy of the log-likelihood

Forward recursive estimation

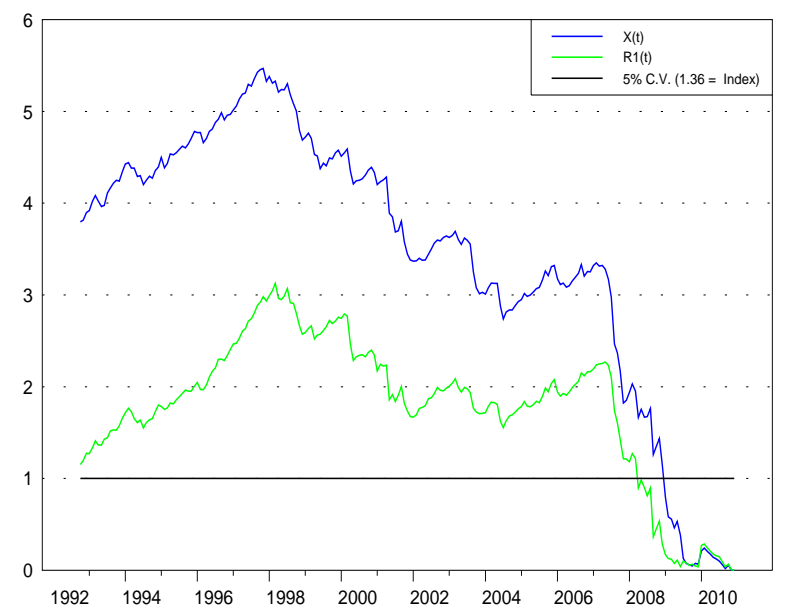

Backward recursive estimation

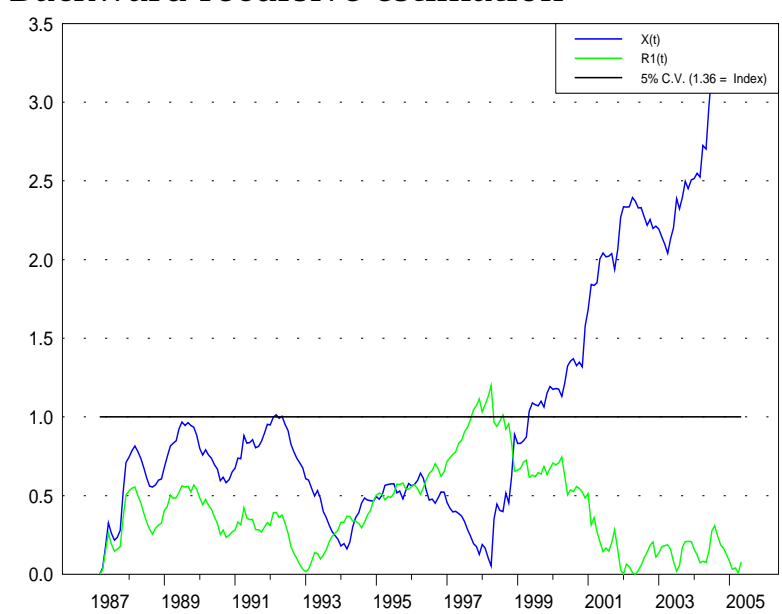

Note: $i$ ) The lowest graph indicates the log-likelihood on $R$-form, meaning that the short-run structure is regressed out (see Juselius (2007, s.151)). ii) The horizontal line determines the $5 \%$ confidence level for a constant log-likelihood (parameter regime). iii) Forward and backward recursive estimation use a baseline-period in 1987:03-1992:10 and 2005:02-2010:09 respectively.

Figure C.2: Test for constancy of the beta-matrix

\section{Forward recursive estimation}

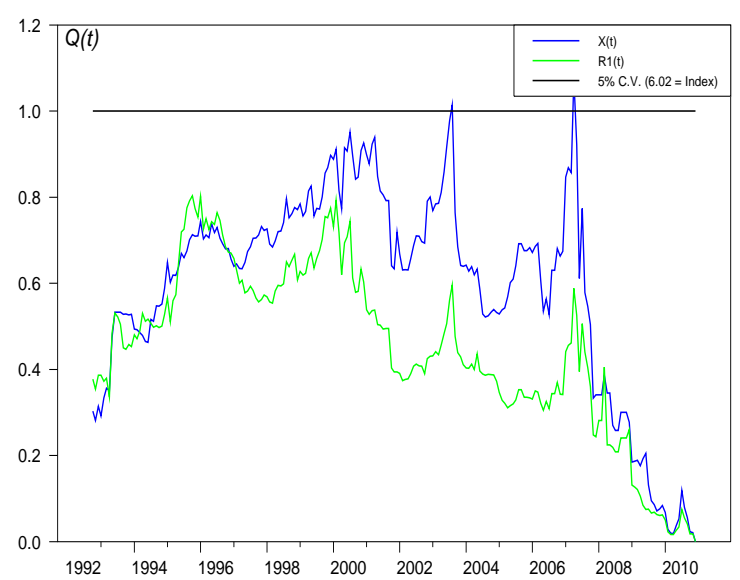

Backward recursive estimation

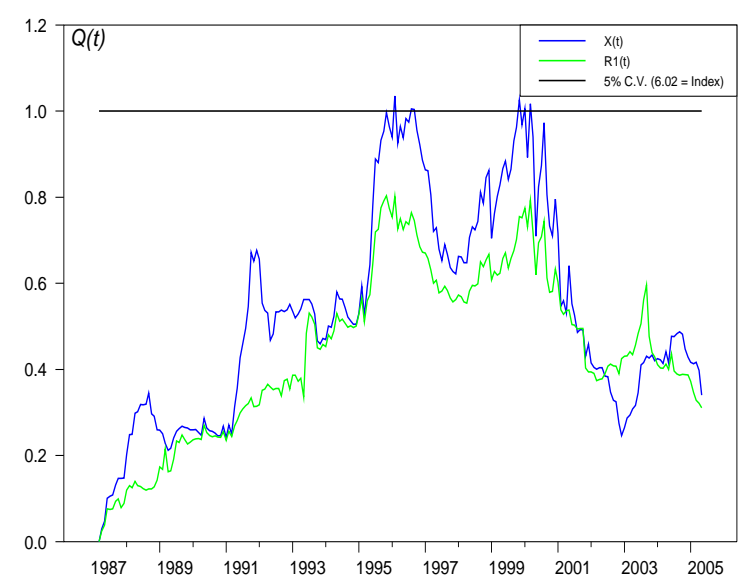

Note: $i$ ) The lowest graph indicates the log-likelihood on $R$-form, meaning that the short-run structure is regressed out (see Juselius (2007, s.151)). ii) The horizontal line determines the $5 \%$ confidence level for a constant $\beta$-matrix. iii) Forward and backward recursive estimation use a baseline-period in 1987:03-1992:10 and 2005:02-2010:09 respectively. 
Figure C.3: Recursive estimation of the $\alpha$-parameters of the $R$-form Forward recursive estimation

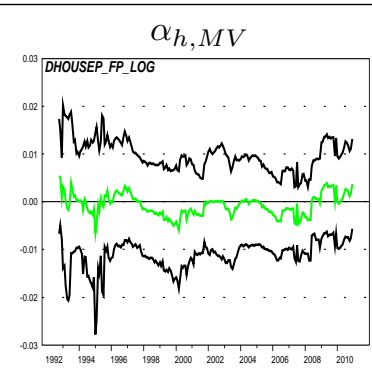

$\alpha_{k, M V}$

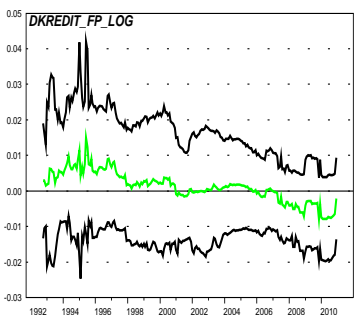

$\alpha_{m, M V}$

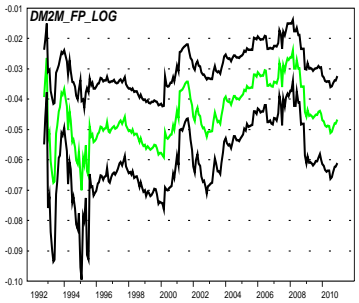

$\alpha_{y, M V}$

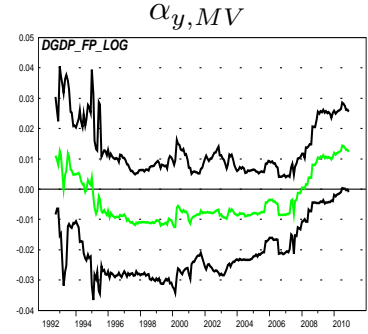

Backward recursive estimation

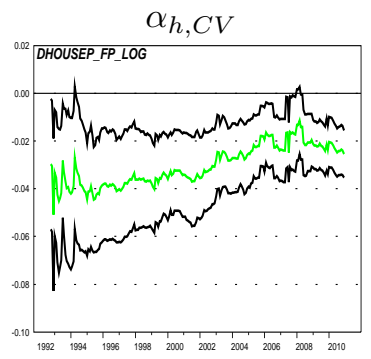

$\alpha_{k, C V}$

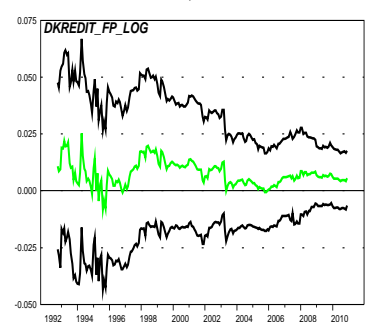

$\alpha_{m, C V}$
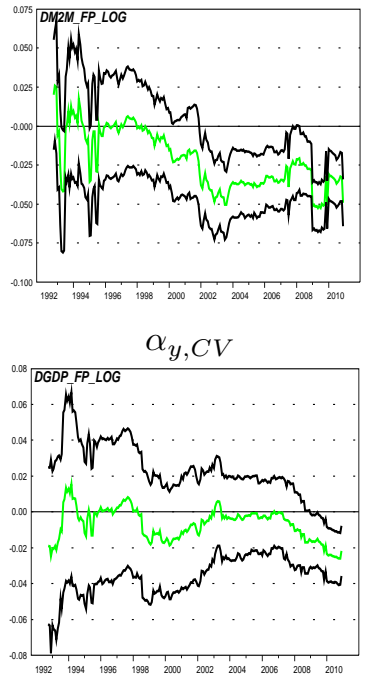

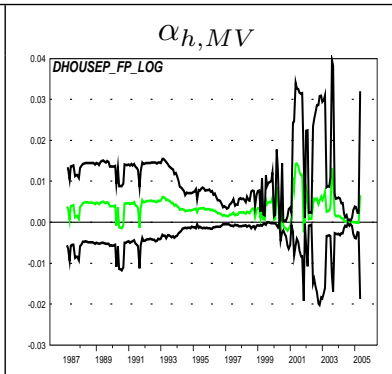

$\alpha_{k, M V}$

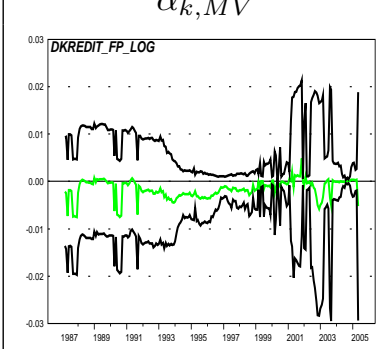

$\alpha_{m, M V}$
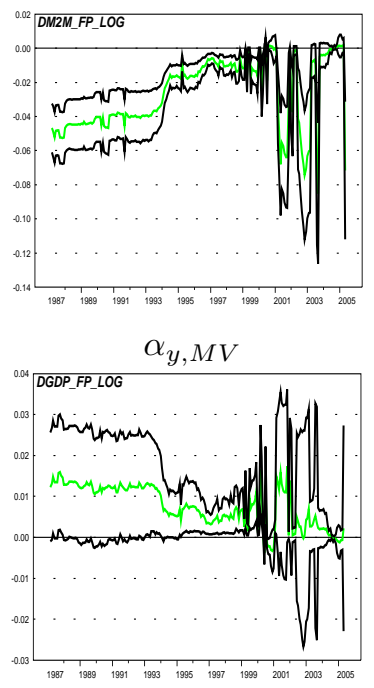

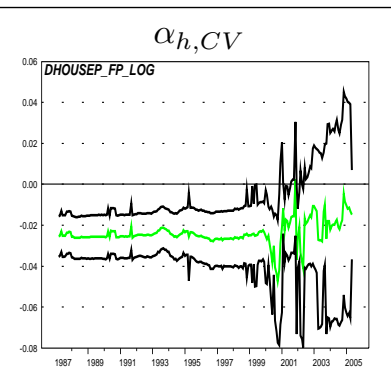

$\alpha_{k, C V}$

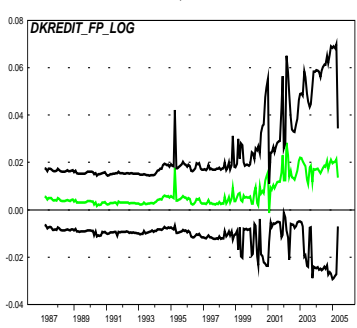

$\alpha_{m, C V}$
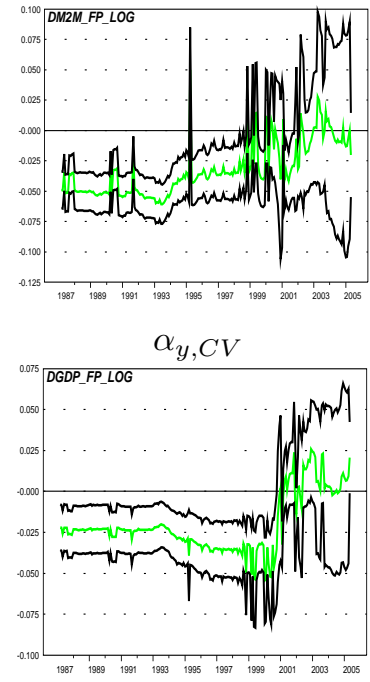

Note: Forward and backward recursive estimation use a baseline-period in 1987:03-1992:10 and 2005:02-2010:09 respectively. The $R$-form means that the cointegration is corrected for short-run parameter; $\Delta x_{t-1}$, dummies, shifts etc. 